\title{
LUIS JIMÉNEZ DE ASÚA: UN PENALISTA A CARGO DE LA CONSTITUCIÓN DE LA II REPÚBLICA
}

\section{LUIS JIMÉNEZ DE ASÚA: A PENOLOGIST IN CHARGE OF THE CONSTITUTION OF THE II REPUBLIC}

\author{
Enrique Roldán Cañizares \\ Universidad de Sevilla
}

\begin{abstract}
Sumario: I. EL PENALISTA Y LA CONSTITUCIÓN. - II. UNA NUEVA CONSTITUCIÓN PARA UNA NUEVA REPÚBLICA. - 2.1. Referencias nacionales y patrióticas. - 2.2. Organización territorial. - 2.3. Derechos y deberes. - 2.4. Organización institucional. - 2.5. Justicia. - III. CONCLUSIONES. LA CONSTITUCIÓN QUE NO FUE.
\end{abstract}

Resumen: Luis Jiménez de Asúa fue el penalista de habla hispana más importante del siglo XX. Sin embargo, su figura no es plenamente conocida dentro de España, pues haberse erigido como uno de los políticos más importantes de la II República y ser un referente de las instituciones republicanas en el exilio se tradujo en su condena al ostracismo por parte del régimen franquista. Este artículo pretende recuperar el papel que Jiménez de Asúa tuvo en la elaboración de la Constitución de 1931, puesto que, con independencia de que su especialidad fuera el derecho penal, fue presidente de la comisión encargada de elaborar el proyecto constitucional republicano. De este modo, a lo largo del texto se pueden encontrar los diferentes aportes que el profesor madrileño hizo en la carta magna republicana, tanto en su papel de presidente, como en el de parlamentario, intentando desentrañar tanto las bases doctrinales como las motivaciones que le guiaron en su cometido.

Abstract: Luis Jiménez de Asúa was the most important Spanish-speaking penologist of the 20th century. However, his figure is not fully known within Spain, as having established himself as one of the most important politicians of the Second Republic and being a reference point for the Republican institutions in exile, resulted in his being ostracised by Franco's regime. This article seeks to recover the role that Jiménez de Asúa played in the drafting of the 1931 Constitution, since, regardless of the fact that his specialty was criminal law; he was president of the commission in charge of drafting the Republican constitutional project. Thus, throughout the text one can find the different contributions that the professor from Madrid made in the Republican Magna Carta, both in his role as president and as a parliamentarian, trying to unravel both the doctrinal bases and the motivations that guided him in his task.

Palabras clave: Luis Jiménez de Asúa, II República, Constitución, Constituciones de entreguerras, Estado Integral, España

Key words: Luis Jiménez de Asúa, II Republic, Constitution, Inter-war Constitutions, Integral State, Spain. 
En la primera noche que Luis Jiménez de Asúa pasó en la oscura celda que le sirvió de hogar durante su confinamiento en las Islas Chafarinas ${ }^{1}$, dificilmente pudo pensar que pocos años más tarde habria de convertirse en el presidente de la comisión parlamentaria encargada de elaborar un proyecto de Constitución para la II República española. Era por aquel entonces un enfervorecido opositor de la dictadura de Primo de Rivera ${ }^{2}$, la cual encontraba en el penalista madrileño a uno de sus peores enemigos, capaz de ilustrar a sus alumnos universitarios con sus amplios conocimientos de derecho penal, al mismo tiempo que los lanzaba a la lucha contra un régimen que les privaba de sus más elementales derechos ${ }^{3}$.

Pero la dictadura cayó, y el papel desempeñado por los estudiantes en unión con las fuerzas obreras, tal y como Jiménez de Asúa había profetizado, fue fundamental para el fin del régimen ${ }^{4}$. En cuanto a su andadura politica, durante los años en los que el dictador jerezano hizo de España su cortijo, Jiménez de Asúa no habia formado parte de las filas del Partido Socialista, limitándose a figurar en las listas de Acción Republicana. Fue tras el colapso de un régimen cada vez más incapaz de sostener una monarquía caduca cuando Jiménez de Asúa se acercó al Partido Socialista. No obstante, no debe caerse en el error de pensar que la defensa de los postulados socialistas por parte del penalista madrileño ocurriera de la noche a la mañana. Desde años atrás había sido firme partidario de los principios enarbolados en España por el partido fundado por Pablo Iglesias Posse, pero era consciente de que, para el triunfo y la implantación del socialismo, habia otras etapas que previamente eran necesarias atravesar.

Esta idea fue defendida en 1927 cuando, en las páginas del diario El Sol, Jiménez de Asúa abogó por la necesidad de una revolución. Pero no se refería a una revolución socialista similar a la que había sacudido Rusia una década atrás, sino de una de tipo burgués que arrancara de raíz el atraso del que España no había podido escapar aún ${ }^{5}$. La llegada de la II República a través de las elecciones municipales del 12 de abril fue esa revolución, en este caso pacífica y democrática, que posibilitó la implantación en España del régimen burgués que

1 A raíz de las críticas lanzadas contra el régimen primorriverista durante sus vistas a Argentina, así como por la actitud combativa mostrada en clase, el directorio militar detuvo de forma irregular a Jiménez de Asúa, confinándolo en las Islas Chafarinas junto con un pequeño número de presos. vid. Luis Jiménez de Asúa, Notas de un confinado, Madrid, Editorial Mundo Latino, 1930, p. 33-35.

2 Con los años y la cruda experiencia de la guerra civil y el franquismo, la percepción negativa de Primo de Rivera se relajó, pasando a definirlo como un general "bonachón e iracundo, liberalote y jaranero" que "como buen señorito, no tenía respeto alguno a los derechos de los demás; pero en principio, y a pesar de sus desmentidos verbales, creía que todo el mundo debía hacer lo que le viniese en gana" vid. Luis Jiménez de Asúa, Anécdotas de las Constituyentes, Buenos Aires, Publicaciones del Patronato hispano-argentino de cultura, 1942, p. 9.

3 Desde la visión de Jiménez de Asúa, el papel de la juventud debía ser determinante en el fin de la dictadura. Siempre consideró que los jóvenes españoles serían el motor de cambio de la sociedad española, preocupándose en apoyarlos y ayudarlos en su lucha con todos los instrumentos que estuvieran en su mano. Vid. Luis Jiménez de Asúa, Juventud, Madrid, Velasco, 1929, pp. 51-77.

${ }^{4}$ Eduardo González Calleja, "La politización de la vida universitaria madrileña durante los años veinte y treinta”, en Eduardo González Calleja y Álvaro Rivagorda Esteban, La Universidad Central durante la Segunda República, Madrid, Dykinson, 2013, pp. 275-277.

5 Sebastián Urbina Tortella, Ética y política en Luis Jiménez de Asúa, Palma de Mallorca, Universidad de Mallorca, 1984, p. 100. 
Jiménez de Asúa pedia. Este deseo, obviamente, no obedecía a las inexistentes pretensiones burguesas del futuro diputado, sino al convencimiento de que una vez arraigado dicho régimen, el paso al socialismo sería posible. En este contexto se afilió al Partido Socialista, y a pesar de haber expresado públicamente su deseo de alejarse de la politica ${ }^{6}$ y regresar a la vida universitaria ${ }^{7}$, tras las insistentes peticiones de Fernando de $\operatorname{los}$ Rios $^{8}$ se presentó a las elecciones a Cortes Constituyentes por la provincia de Granada. Así se convirtió de la noche a la mañana en un político que hubo de recorrer diferentes pueblos de la provincia pidiendo el voto para sí y para el socialismo, que a sus ojos no era ni un simple partido, ni siquiera una ideología, sino la única civilización en la que el hombre podría ser verdaderamente libre ${ }^{9}$.

Con este planteamiento en la mente de Jiménez de Asúa comienza la Segunda República, sobre la que se ha aseverado con acierto que "fue el primer intento de fundar entre nosotros (...) un Estado constitucional en el que el juego político quedase racionalizado"10. De esta afirmación se desprende, no solo la idea de racionalización de poderes planteada por Boris Mirkine Guetzévitch ${ }^{11}$, sino también el intento de superación del sistema político e institucional de la Restauración ${ }^{12}$. Los mismos prohombres de la República que aceptaron con honor el nuevo cometido que tenian entre manos como diputados de las Cortes Constituyentes, fueron conscientes de la importancia del momento que atravesaba España, e incluso de la necesidad estructural del mismo ${ }^{13}$. De esta forma, dio comienzo uno de los periodos políticos más intensos de la historia reciente de nuestro país, donde la calidad discursiva y la riqueza de propuestas no hizo sino ratificar el fuerte compromiso de los representantes elegidos por el pueblo, consciente a su vez de que se encontraba ante la posibilidad de redefinir el Estado españolit.

\footnotetext{
6 Ante la entrada en la cárcel del Comité Revolucionario, Jiménez de Asúa formó parte del II Comité que se conformó, llegando incluso a organizar reuniones en su propia casa. Sin embargo, sus propias palabras sobre el papel desempeñado son meridianamente claras: "nada hicimos y creo que fue nuestra mejor faena" vid. Luis Jiménez de Asúa, Anécdotas de las Constituyentes, op. cit., p. 12 .

7 Luis Jiménez de Asúa, "Retorno a la ciencia”, La Libertad, 17 de abril de 1931.

8 Luis Jiménez de Asúa, Anécdotas de las Constituyentes, op. cit., p. 15.

9 Diario de Sesiones de las Cortes Constituyentes, 27 de agosto de 1931, n 28, p. 645.

10 Luis I. Gordillo, Sebastián Martín y Víctor Vázquez, "La Segunda República desde el derecho ochenta y cinco años después", en Luis I. Gordillo, Sebastián Martín y Víctor Vázquez, Constitución de 1931: estudios jurídicos sobre el momento republicano español, Madrid, Marcial Pons, 2017, p. 19.

11 El profesor nacido en Kiev expresaba la necesidad de que existiera no solo una democracia de hecho, sino una "democracia de derecho", donde se diera una "racionalización jurídica de la voluntad general". vid. Boris Mirkine-Guetzévitch, "Prólogo" en Las nuevas Constituciones del mundo, Madrid, Ed. España, 1931, p. 7.
}

12 Andoni Pérez Ayala, "La Constitución republicana de 1931 siete décadas después", Bilbao, Universidad del País Vasco, Cuadernos republicanos, $\mathrm{n}^{\circ}$ 19, 2002, pp. 13-34.

13 José Manuel Pérez-Prendes Muñoz-Arraco, Escritos de historia constitucional española, Madrid, Marcial Pons, 2017, p. 334.

14 Giacomo Demarchi, "La segunda república y su(s) territorio(s): los múltiples actores del Estado integral”, en Luis I. Gordillo, Sebastián Martín y Víctor Vázquez, Constitución de 1931: estudios jurídicos sobre el momento republicano español, op. cit., p. 186. 
Con el objetivo de dotarse de una carta constitucional que cumpliera con todas las aspiraciones del pueblo español, un decreto fechado en 6 de mayo de 1931 creó una Comisión Jurídica Asesora que, como sustituta de la Comisión de Códigos, habría de encargarse de dar unidad técnico-jurídica a las disposiciones emanadas de los distintos departamentos ministeriales". Su primer cometido fue la elaboración de un anteproyecto de Constitución, en cuyos artículos y votos particulares se hicieron bien patentes las posiciones jurídico-politicas de los 13 miembros que la componian, entre los que destacaban su presidente Ángel Ossorio y Gallardo, quien se llegó a denominar a sí mismo como un "monárquico sin rey"15, y Adolfo González Posada, el eminente catedrático de derecho constitucional que junto a su discípulo Nicolás Pérez Serrano ya se había encargado de dar a conocer en España las nuevas Constituciones de posguerra ${ }^{16}$ que habian surgido durante los años previos, las cuales, concretamente las de Weimar, Checoslovaquia, México y Austria, tendrian una influencia notoria en el texto republicano de diciembre de $1931^{17}$.

En una comisión en la que predominaron precisamente las ideas de Adolfo Posada, Nicolás Pérez Serrano definió el anteproyecto como "una obra seria, correcta, congruente, de perfil no muy extremoso en radicalismos, pero absolutamente respetable, y quizás más armónica de líneas, y más sistemática en su orientación que el proyecto redactado después por la comisión parlamentaria"18. Sin querer entrar todavía a analizar el proyecto elaborado por la comisión a la que se refería Pérez Serrano, es innegable que el anteproyecto liderado por Ossorio y guiado por Posada no consiguió contentar al Gobierno, quizá por su evidente conservadurismo, por su patente irrealismo en algunos aspectos como el referido al derecho eclesiástico o sencillamente por darse por descontado un rotundo rechazo parlamentario ${ }^{19}$. El propio Jiménez de Asúa, cuando todavía no podía ni imaginar que desempeñaría un papel crucial en la redacción de la carta política del régimen republicano, asistió a una de las sesiones del pleno para hacer constar que, si bien el contenido técnico del anteproyecto le parecía laudable, no compartía los principios políticos que orientaban su articulado ${ }^{20}$. En esta línea, es evidente que el objetivo inicial del Gobierno era convertir el anteproyecto en proyecto, para así presentarlo como una ponencia ministerial, pero las discrepancias surgidas entre los ministros de diferente espectro ideológico que conformaban el Gobierno -alguno de ellos llegó a

15 Luis Jiménez de Asúa, Proceso histórico de la Constitución de la República española, Madrid, Reus, 1932, p. 4.

16 Nicolás Pérez Serrano y Carlos González Posada, Las Constituciones de Europa y América, Madrid, V. Suárez, 1927, con estudio preliminar de Adolfo González Posada.

17 Joaquín Varela Suanzes-Carpegna, "El constitucionalismo español en su contexto comparado", Documentos de Trabajo IELAT (Instituto Universitario de Investigación en Estudios Latinoamericanos), $\mathrm{n}^{\mathrm{o}}$ 13, 2010, pp. 1-26.

18 Nicolás Pérez Serrano, La Constitución española. Antecedentes, textos, comentarios, Madrid, Editorial Revista de Derecho Privado, 1932, p. 23.

19 El propio Adolfo Posada aseguró que el anteproyecto se enmarcaba en la tradición constitucional integrada por las Constituciones de 1812, 1837 y 1869, aunque en Título III, versante sobre los derechos y deberes de los españoles, suponía una revolución de calado en el derecho político. Vid. Santos Juliá, La Constitución de 1931, Madrid, Iustel, 2009, p. 39.

20 Luis Jiménez de Asúa, Proceso histórico de la Constitución de la República española, op. cit., p. 3. 
tildarlo de texto "retardatario, reaccionario y confuso"21- llevaron al traste tal posibilidad $^{22}$.

Fue entonces cuando llegó el momento más inesperado de la vida de Jiménez de Asúa como político, quien previamente había dicho sobre el anteproyecto que, a pesar de usar un molde completamente nuevo, el contenido seguía siendo viejo ${ }^{23}$. No importó que repitiera hasta la saciedad que la Comisión Permanente de Justicia era el destino ideal para que pudiera aportar sus conocimientos a la República que acababa de nacer. Fue elegido miembro de la comisión encargada de dar forma al nuevo proyecto constitucional ${ }^{24}$, y lo que fue para él más inesperado: poco después fue designado como su presidente, encargándose de forma casi inmediata de "rejuvenecer" sus conocimientos sobre derecho constitucional mediante las lecturas de los trabajos de autores como Adolfo Posada, Nicolás Pérez Serrano y Mirkine Guetzévitch. Por otra parte, el propio Jiménez de Asúa reconoció que la asistencia de Miguel Cuevas, quien desempeñaba el cargo de Oficial técnico de la Secretaría del Congreso junto a Pérez Serrano, fue de gran ayuda tanto para la organización de las lecturas rejuvenecedoras como para la posterior preparación del discurso con el que hubo de presentar el proyecto ante las Cortes $^{25}$. Jiménez de Asúa no confiaba en poder desempeñar correctamente su nuevo cometido, pero su compañero Luis Araquistáin no dudó en reconocer que "su imparcialidad, su autoridad científica, su espíritu metódico, su ingenio ocurrente, su severidad humorística, que una mañana le llevó nada menos que a romper una campanilla, con gran algazara de la comisión, evitaron más de una vez, en el dramatismo con que discutí[an] los primeros días, que la pasión política o la idiosincrasia individual comprometieran la buena marcha del proyecto" 26 . El PSOE no solo había dado el paso hacia la colaboración con el Gobierno, tal y como había propuesto Indalecio Prieto en el Congreso extraordinario que el partido celebró poco antes de la apertura de las Cortes $^{27}$, sino que escasos meses después había conseguido que un miembro de su formación presidiera la comisión encargada de dotar a la República de una Constitución.

21 Javier Infante Miguel-Motta, "Un hito en la historia constitucional de España: el derecho de propiedad en la Constitución republicana de 1931", en Luis I. Gordillo, Sebastián Martín y Victor Vázquez, Constitución de 1931: estudios jurídicos sobre el momento republicano español, op. cit., p. 303. 25.

22 Nicolás Pérez Serrano, La Constitución española. Antecedentes, textos, comentarios, op. cit., p.

23 Luis Jiménez de Asúa, Proceso histórico de la Constitución de la República española, op. cit., p. 23.

${ }^{24}$ De hecho, con el tiempo se le ha llegado a considerar de forma errónea como un "prestigioso constitucionalista". Vid. Eduardo González Calleja, Francisco Cobo Romero, Ana Martínez Rus y Francisco Sánchez Pérez, La Segunda República española, Barcelona, Pasado y Presente, 2016, p. 85.

25 Giacomo Demarchi, “Técnicos parlamentarios y Cortes constituyentes: Miguel Cuevas y Cuevas en la forja del constitucionalismo de la II República”, en Diana Repeto García, Las Cortes de Cádiz y la historia parlamentaria, Cádiz, Universidad de Cádiz, 2012, pp. 629-638.

26 Luis Araquistain, "Anécdotas de la política. Cómo elaboramos el proyecto de Constitución”, El Sol, 8 de diciembre de 1931, p. 1.

27 Manuel Tuñón de Lara, “El sistema de partidos es 1931-1933”, Historia contemporánea, $\mathrm{n}^{\circ}$ 6, 1991, pp. 59-84. 


\section{I - EL PENALISTA Y LA CONSTITUCIÓN}

“Todos los hombres tenemos derecho a cultivar una manía. A mí me aqueja la de ser sincero. Por ello me urge decir (...) que yo no soy especialista en derecho constitucional"28. Con estas palabras iniciaba Jiménez de Asúa el libro con el que, al año siguiente de haberse aprobado la Constitución, explicaba los pormenores del proceso constituyente. En el mismo instante en el que fue nombrado miembro de la comisión de Constitución tuvo inquietud por conocer por qué el Gobierno no había sido capaz de componer un proyecto que bebiera de todas las corrientes políticas que le daban forma. La respuesta con la que se encontró fue simple: en un grupo de ministros entre los que tenía cabida el conservadurismo, la izquierda de Azaña, el socialismo, los radicales de Lerroux y los radical-socialistas, no era posible componer un proyecto de Constitución sin "riesgo de discrepancia". De hecho, el propio Gobierno confirmó que no presentaría ninguna ponencia a las Cortes, reservándose los ministros la posibilidad de defender, en calidad de parlamentarios, sus diferentes puntos de vista, así como los de sus respectivos partidos ${ }^{29}$. Ante esta tesitura llegó incluso a plantearse por qué tras unas elecciones en las que la izquierda resultó victoriosa, Niceto Alcalá-Zamora y Miguel Maura seguían en el Gobierno30; aunque la conciencia de la dificultad del momento por el que atravesaba España dejó a un lado las tentaciones de reprobación.

La imposibilidad de que ni siquiera los miembros del Gobierno provisional pudieran llegar a un consenso sobre la nueva carta fundamental hundió en el desasosiego a Jiménez de Asúa. Si los máximos dirigentes de la República no eran capaces de ponerse de acuerdo, ¿cómo iban a hacerlo 21 comisionados entre los que, además de republicanos y socialistas, figuraban partidos que no habian apostado por la República? Cinco socialistas, cuatro radicales, tres radicalsocialistas, dos miembros de la minoría catalana y uno de la minoría gallega, un federal, un miembro de Acción Republicana, un progresista (nombre con el que paradójicamente se designaron los seguidores de Alcalá-Zamora), un componente de la Agrupación al Servicio de la República, un miembro de la minoría vasconavarra y un agrario ${ }^{31}$. Las Cortes eligieron el 28 de julio, de forma proporcional, a la compleja pléyade de representantes que habrian de elaborar un proyecto que presentar para su debate. Si en ese momento Jiménez de Asúa ya tenía dudas sobre la viabilidad del cometido, el miedo le azuzó cuando en la primera reunión de la comisión todos sus miembros le eligieron para la presidencia por unanimidad $^{32}$. Alli estaba él, un penalista que debía dirigir los trabajos de los constituyentes con el objetivo de llegar al consenso que no pudieron alcanzar los miembros del Gobierno provisional.

28 Luis Jiménez de Asúa, Proceso histórico de la Constitución de la República española, op. cit., p. IX.

29 Luis Jiménez de Asúa, La Constitución de la democracia española y el problema regional, Buenos Aires, Editorial Losada, 1946, p. 17.

30 Luis Jiménez de Asúa, Anécdotas de las Constituyentes, op. cit., pp. 22-24.

31 Luis Jiménez de Asúa, Proceso histórico de la Constitución de la República española, op. cit., pp. 34-35.

32 Luis Jiménez de Asúa, Anécdotas de las Constituyentes, op. cit., p. 25. 
Antes de iniciarse en los trabajos de la comisión, Jiménez de Asúa tenía claro que la naciente República debia enfrentarse a cuatro grandes dificultades que España venía arrastrando tiempo atrás: la reforma militar, la cuestión religiosa, el problema agrario y el asunto regional ${ }^{33}$.

El tema de la reforma militar fue, según Jiménez de Asúa, felizmente resuelto durante los primeros compases de la República. Era evidente que el intervencionismo del ejército en la historia política reciente de España debía tocar a su fin en un régimen democrático como el republicano, de manera que las primeras disposiciones de Manuel Azaña como ministro de Guerra estuvieron encaminadas a tal efecto ${ }^{34}$. La profunda reforma técnica, "y no politica", (un hecho que Jiménez de Asúa siempre remarcó) fue a ojos del profesor madrileño una necesidad de España, así como la eficaz forma en la que la República solucionó un "angustioso problema previo" que podría tener repercusiones en el futuro. "Lo que durante muchos años fue deseo de los españoles, lo logró la República en los primeros instantes de su implantación". No cabe duda de que buena parte de la sociedad española deseaba una reforma del tal calado; sin embargo, el generalato tardaría en tomarlo como una afrenta, sembrando la semilla de un odio que terminaría explotando en el verano de 1936.

El segundo de los asuntos tenía su razón de ser en la relación entre el Estado y la Iglesia católica. La penetración de la religión en la política española había sido una constante desde tiempos inmemoriales, y, de hecho, la última Constitución vigente antes de 1931 seguía declarando la religión católica como la oficial del Estado; una situación que tampoco cambió durante la Dictadura de Primo de Rivera.

En tercer lugar, el problema agrario conformaba otra de las grandes preocupaciones de Jiménez de Asúa. En consonancia con la idea previamente planteada de que en España no había tenido lugar ninguna revolución de carácter burgués, el flamante presidente de la comisión de Constitución creía que las propiedades de carácter rural todavía no habian evolucionado a la fase burguesa tal y como había ocurrido en gran parte de Europa a raíz de 1789. El antiguo noble seguía ostentando poder por el hecho de ser un terrateniente, y la República, como moderno régimen de carácter democrático, debía poner fin a tal situación.

Finalmente, el cuarto problema acuciante que debía afrontar la República no era otro que el regional. A ojos de Jiménez de Asúa, el hecho de que Primo de Rivera hubiera prometido autonomía plena a los catalanes, para posteriormente perseguir el uso del idioma e impedir cualquier tipo de estatuto autónomo, había herido de forma innegable las "fibras sentimentales de Cataluña". De este modo, había conseguido que en Cataluña se engendrara un "infundado enojo contra el resto de España"35, al igual que había provocado afanes autonómicos en los

33 Luis Jiménez de Asúa, La Constitución de la democracia española y el problema regional, op. cit., pp. 57-66.

34 A tal respecto debe ser descatados Michael Alpert, La reforma militar de Azaña (1931-1933), Madrid, Siglo XXI, 1982, pp. 121-136, así como Santos Juliá, Manuel Azaña. Una biografía politica, Madrid, Alianza editorial, 1990, p. 99.

35 Luis Jiménez de Asúa, La Constitución de la democracia española y el problema regional, op. cit., pp. 62-64. 
territorios vascos y en Galicia. Así las cosas, la nueva República debía alcanzar un punto común con las peticiones de autonomia. Se hacía necesaria una transacción que, al mismo tiempo que no renunciara a la unidad de España, hiciera posible ciertos grados de autonomía dentro de las regiones en cuestión; una postura que se había vuelto innegociable a raíz de la participación catalana en el Pacto de San Sebastián.

No cabe duda de que los problemas que Jiménez de Asúa entendía como cruciales también estaban en la mente de la gran mayoria de los miembros de las Cortes y del Gobierno provisional. Sin embargo, el modo de afrontarlos fue la gran diferencia que le separó del resto. El profesor madrileño consideraba que el pueblo español, en lugar de optar por una revolución que hubiera desembocado en enfrentamientos callejeros, habia elegido el proceso democrático y la representación de sus anhelos a través de sus politicos como el modo ideal para alcanzar las conquistas esperadas. Por lo tanto, la resolución de los grandes problemas de España no debía hacerse exclusivamente a través de su inclusión en la Constitución, sino que debían ser los representantes populares los que, a través de la publicación de decretos-leyes, fueran dando forma a las necesidades ciudadanas que habían posibilitado el cambio de régimen. Si se promulgaban los decretos-leyes que la nueva República necesitaba, los avances sociales, politicos y democráticos que dependian de ellos podrian ponerse en funcionamiento de forma inmediata, sin necesidad de esperar a su inclusión en la Constitución, y sin depender de la "juridicidad"36. Con el paso de los años Jiménez de Asúa llegó a lamentarse de no haber hecho públicas sus reflexiones al respecto: "Debi haberlas gritado desde mi asiento del Congreso y haberlas repetido por escrito en todos los periódicos de Madrid y de las provincias"37. Pero en lugar de hacerlo, cuando la comisión le nombró presidente, aceptó su cargo y entendió que más allá de las ideas personales, debía predominar la lealtad a la República: independientemente de que creyera que está "revolución desde arriba" (tomando las palabras de Antonio Maura) "era una frase tan elegante como falsa", pues "jamás un grupo de hombres tuvo más propicios a los de abajo para que desde arriba viniera una revolución ordenada y eficiente"38.

El método de trabajo que se organizó en un primer momento, en connivencia con Alcalá-Zamora, fue del agrado de Jiménez de Asúa. Los diferentes títulos de la Constitución se irían presentando individualmente para su sometimiento a discusión. Posteriormente, una vez que todo el texto constitucional estuviera redactado, se debatirian todos en una segunda lectura. Si para Jiménez de Asúa "una Constitución [era] la vestidura jurídico-política de un pueblo, la garantía de

\footnotetext{
36 Por considerarla como el principal hecho que impedía la puesta en marcha de las politicas prometidas por la República, Jiménez de Asúa siempre usó despectivamente el término juridicidad: "La palabra, que rodó luego por los escaños de las Constituyentes, por las planas de los periódicos, y que fue mordida con el odio del freno por el pueblo español, era, al desenredarse de la barba mora de don Ángel Ossorio, un vago esquema de "justicidad", en los labios de otros abogados, la personificación de la "legalidad", y en el chasqueo de otras lenguas, la traba reaccionaria. En última instancia, los que la identificaban con la legalidad servían indirectamente a los del último grupo, porque no habiendo aún legislación republicana, la legalidad era monárquica, y, por ende, conservadora: vid. Luis Jiménez de Asúa, Anécdotas de las Constituyentes, op. cit., pp. 24-25.
}

37 Luis Jiménez de Asúa, Anécdotas de las Constituyentes, op. cit., p. 30.

38 Ibid., p. 33. 
las conquistas logradas y una traba contra la arbitrariedad de los gobernantes"39, era lógico que pidiera tiempo y prudencia para su elaboración. Así fue, de hecho, durante la primera semana de trabajo de la comisión. Decidiendo apoyarse en el anteproyecto de la Comisión Jurídica Asesora, así como en sus votos particulares $^{40}$ (pues si bien el contenido político-democrático era escaso, juzgaba que la calidad técnica era innegable sobre todo en estos últimos) ${ }^{41}$, la comisión trabajó durante la primera semana respetando los descansos parlamentarios. Es decir, se reunian de martes a viernes en horario matutino ${ }^{42}$, sin sobrepasar los límites estipulados por el reglamento del Congreso, en el Salón de Sesiones. No obstante, el trabajo que Jiménez de Asúa realizaba junto con el resto de comisionados socialistas iba más allá de las meras reuniones. Éstos se reunían con anterioridad a la propia comisión, estudiaban los artículos que posteriormente debían abordarse y llevaban los debates a la comisión en forma de enmienda de los artículos del anteproyecto o del voto particular en cuestión; una misión que, a pesar de que la comisión fuera un "modelo de cordialidad", en palabras de Jiménez de Asúa se convirtió en una "tarea agotadora"43.

Pero la situación no tardó en cambiar. Solo se habían celebrado cinco sesiones cuando el Gobierno requirió la presencia de Jiménez de Asúa. Alcalá-

39 Ibid., p. 28.

40 Así se explica en Luis Araquistain, "Anécdotas de la política. Cómo elaboramos el proyecto de Constitución", El Sol, 8 de diciembre de 1931, p. 1. Además, cabe destacar el hecho que Manuel Pedroso, correligionario de Jiménez de Asúa, firmó varios de los votos particulares. En esta línea se puede destacar un voto particular a la totalidad del Título I en el que se planteaba una nueva estructura con 14 artículos y se proponía un régimen más "federable" que el recogido en el anteproyecto. De forma individual también presentó dos votos particulares al Título II buscando una ampliación de los modos de adquisición de la nacionalidad. De igual modo firmó junto a otros miembros de la Comisión un voto referido al Título III proponiendo, entre otros asuntos, la protección del Tesoro nacional o la prohibición del acaparamiento de tierras. En relación al artículo que regulaba la propiedad, propuso una "fórmula de tipo más socializante", y junto con Matilde Huici, Niceto Alzalá-Zamora y Castillo y Arturo Rodríguez Muñoz firmó un voto particular que hacía incompatible la enseñanza con el trabajo de todo niño menor de 14 años. Igualmente, formó parte del voto particular a la totalidad del Título IV que proponía la construcción de un sistema legislativo unicameral, así como del voto particular que, en reacción al Título V, buscaba fortalecer la figura del presidente de la República. Finalmente, también firmó el voto particular que, versando sobre el contenido del Título VI, pedía la creación de los denominados Consejos técnicos, al igual que ocurrió con un voto sobre el Título VIII que buscaba la prohibición del régimen de cupos y conciertos en lo referente a los tributos. Vid. Luis Jiménez de Asúa, Proceso histórico de la Constitución de la República española, op. cit., pp. 28-33.

41 El reconocimiento de Jiménez de Asúa hacia la calidad técnica del anteproyecto fue público y notorio. Sin embargo, entendía que algunos elementos del anteproyecto tales como el régimen bicameral, el estatuto de corporación de derecho público que se le atribuyó a la Iglesia y el simple reconocimiento de la función social de la propiedad (aspectos en los que profundizaré más adelante) no podía, en palabras de Sebastián Martín, "satisfacer el anhelo reformista de la revolución republicana". vid. Sebastián Martín, "Modernización doctrinal, compromiso técnico, desafección politica. Los juristas ante la Segunda República”, en Luis I. Gordillo, Sebastián Martín y Víctor Vázquez, Constitución de 1931: estudios jurídicos sobre el momento republicano español, op. cit., p. 65.

42 En los documentos sobre el proceso constituyente que se pueden consultar en el Congreso de los Diputados, son varias las notificaciones escritas por Jiménez de Asúa en las que citaba a los comisionados entre las 10 y las 10 y 30 de la mañana. Vid. Archivo del Congreso de los Diputados, P-01-000539-0001-0001-012, pp. 15-20.

43 Luis Jiménez de Asúa, Proceso histórico de la Constitución de la República española, op. cit., pp. 37-38. 
Zamora, en nombre de todos los ministros, así como en el suyo propio, le instó a que la tarea quedara conclusa en el plazo de dos semanas. El gobierno nada podía exigirle realmente, pues su mandato procedía del Poder Legislativo, que era el que había creado la comisión ${ }^{44}$, pero las presiones también existentes desde la prensa, ansiosa de novedades relativas a la nueva Constitución, así como de otros diputados, llevaron a Jiménez de Asúa a aceptar la encomienda gubernamental ${ }^{45}$. Fue así como comenzaron los trabajos forzados de la comisión. Ésta empezó a trabajar mañana y tarde incluso durante los domingos, y el propio Jiménez de Asúa reconoció que fue en su "retiro de El Escorial" donde "fueron compuestos los artículos de familia, economía y cultura".

El 18 de agosto fue entregado el proyecto parlamentario. No obstante, el día 14 ya habian concluido la redacción del articulado y fue durante los días 15 y 17 cuando, en el proceso de ordenación y redacción definitiva, nació la idea de crear un Título preliminar ${ }^{46}$. Fueron 20 los días que la comisión tardó en redactar el proyecto de Constitución, un periodo extremadamente eximio para tal coyuntura y al que Nicolás Pérez Serrano achacó las "deficiencias notorias"47. El propósito de Jiménez de Asúa era utilizar en torno a unos dos meses para el trabajo en la comisión, de manera que la posterior discusión parlamentaria no pasara de un $\mathrm{mes}^{48}$. No se tuvo en cuenta su propuesta y las Cortes se enfrascaron en tres largos meses de discusiones parlamentarias, sin obviar el hecho de que con más tiempo se podría haber obtenido un proyecto mucho más elaborado ${ }^{49}$, tal y como denunciaron diputados (que también formaron parte de la comisión) como Ricardo Samper, quien dijo respecto del proyecto que "faltó reflexión y tiempo", o Emiliano Iglesias Ambrosio, quien "se dolió de que la comisión no hubiera entrado a fondo en ningún asunto"50.

El propio Nicolás Pérez Serrano, en el amplísimo análisis de la Constitución republicana que realizó al poco tiempo de su promulgación, indicó que los temas que más apasionaron en el seno de la comisión fueron el laicismo, la federalización, el radicalismo socializador en referencia a los derechos y deberes y el unicameralismo ${ }^{51}$. Pero el hecho de que estos asuntos fueran los más

44 No debe olvidarse que el proyecto sobre el que la Comisión trabajaba no se trataba de un dictamen sobre una iniciativa parlamentaria, sino de una obra de la Cámara que la Comisión había realizado por delegación de la primera. vid. Nicolás Pérez Serrano, La Constitución española. Antecedentes, textos, comentarios, op. cit., p. 29.

45 Luis Jiménez de Asúa, La Constitución de la democracia española y el problema regional, op. cit., p. 77.

46 Luis Jiménez de Asúa, Proceso histórico de la Constitución de la República española, op. cit., pp. 38-39.

47 Nicolás Pérez Serrano, La Constitución española. Antecedentes, textos, comentarios, op. cit., p. 27.

48 En el propio discurso de presentación del proyecto en las Cortes Jiménez de Asúa recalcó el poco tiempo empleado por la comisión en comparación con otros países del entorno. Así, en Alemania emplearon tres meses y medio, once fueron los meses transcurridos Letonia, dos los utilizados en Polonia, al igual que en Yugoslavia. Vid. Diario de Sesiones de las Cortes Constituyentes, 27 de agosto de 1931, p. 647.

49 Luis Jiménez de Asúa, Anécdotas de las Constituyentes, op. cit., p. 32.

50 Nicolás Pérez Serrano, La Constitución española. Antecedentes, textos, comentarios, op. cit., p. 28.

51 Ibid., p. 28. 
recurrentes dentro de los debates de la comisión no se deben a la mera casualidad, sino al contexto existente cuando la República echó a andar. Las Constituciones son hijas de su tiempo, y la Constitución de 1931 fue hija del periodo de entreguerras, donde Constituciones como la de Weimar, Finlandia, Austria, Checoslovaquia, Estonia, Polonia, Rumanía o México, marcaban el camino a seguir con sus "modernas tendencias"; y donde los fundamentos del Derecho constitucional eran aún discutidos entre los juristas ${ }^{52}$.

Por otra parte, las insuficiencias democráticas de buena parte de los sistemas existentes hasta el estallido de la Gran Guerra, la organización y el aumento de poder de la clase obrera, y la necesidad de un control estatal de la economía más fuerte y eficaz impedian que los cambios que la nueva sociedad surgida de las ruinas necesitaba pudieran encontrarse en una mera revisión del derecho constitucional existente 53 , de ahi que surgiera un constitucionalismo de nuevo cuño. Según Guetzevitch, en este conjunto de Constituciones (aunque él no incluía la mexicana), existían una serie de tendencias comunes tales como la racionalización de poder, la primacía del parlamentarismo, la constitucionalización de lo social, la protección reforzada de la Constitución y la introducción del Derecho Internacional en el ámbito de la Constitución ${ }^{54}$. No mintió Jiménez de Asúa cuando dijo que tras ser nombrado miembro de la comisión se lanzó al estudio de los trabajos, entre otros, de Mirkine-Guetzevitch, pues todos los caracteres enumerados previamente encontraron su acomodo en el proyecto dirigido por el profesor madrileño.

\section{II - UNA NUEVA CONSTITUCIÓN PARA UNA NUEVA REPÚBLICA}

Creo que para una mejor comprensión del papel de Jiménez de Asúa en la elaboración de la Constitución republicana no es conveniente realizar una división entre el periodo en el que la comisión elaboró el articulado y los tres meses de debate parlamentario. Ambos procesos se entremezclan, como bien lo demuestra el hecho de que el discurso de presentación del proyecto en las Cortes, calificado por Pérez Serrano y Adolfo Posada como "excelente" 55 , hiciera las veces de preámbulo, el cual no pudo ser redactado por la acuciante falta de tiempo. De igual modo, esta aseveración queda demostrada por la propia actividad de los comisionados, quienes siguieron realizando reuniones previas a los debates parlamentarios, aunque la inasistencia de algunos de los miembros disgustara a un Jiménez de Asúa que llegó incluso a amenazar con su dimisión 56 . Además, las

52 Abraham Barrero Ortega, "La defensa extraordinaria de la República", Luis I. Gordillo, Sebastián Martín y Víctor Vázquez, Constitución de 1931: estudios jurídicos sobre el momento republicano español, op. cit., p. 232.

53 Javier Corcuera Atienza, "El constitucionalismo de entreguerras y la Constitución española de 1931", Historia contemporánea, n 6, 1991, pp. 15-46.

54 Boris Mirkine-Guetzevitch, Modernas tendencias del Derecho constitucional (1931), Madrid, Reus, 2011, pp. 41-85.

55 Nicolás Pérez Serrano, La Constitución española. Antecedentes, textos, comentarios, op. cit., p. 29 y Adolfo Posada, La nouvelle Constitution espagnole, París, Libraire du Recueil Sirey, 1932 , p. 115 .

56 El 13 de noviembre de 1931 Jiménez de Asúa escribía la siguiente minuta: "No es desconocido (...) el inútil esfuerzo que vengo haciendo para poder reunir la Comisión de Constitución. A menudo se da el caso de que miembros de ella que no han asistido, se ponen en 
diferentes propuestas que nacían en el seno de la comisión por indicación de Jiménez de Asúa no se pueden comprender plenamente sin atender a sus disertaciones parlamentarias, las cuales, a pesar de las críticas de Manuel Azaña ${ }^{57}$, son fundamentales para comprender la razón de ser de sus propuestas. Desde aquel momento en el que segundos antes de subir al estrado no acertaba a encender un cigarro por los nervios, hasta la aprobación definitiva de la Constitución, Jiménez de Asúa entró de lleno en el mundo político, nada más y nada menos que encargándose de dotar a la República de una Constitución. Además, él mismo se encargaba con celo de anotar las modificaciones que las enmiendas iban haciendo sobre el texto. Al trabajar sin libro de actas ni auxiliares mecánicos, todas las enmiendas, así como los nuevos artículos estaban escritos de su puño y letra en el proyecto original que había surgido de la Constitución. No obstante, este modo de trabajar estuvo a punto de suponer una desgracia para las Cortes Constituyentes, pues una mañana en la que se dirigía al Parlamento, Jiménez de Asúa olvidó en el taxi la cartera de piel en la que transportaba el único texto del proyecto que incluía enmiendas, anotaciones y nuevos artículos. Tras llegar a las Cortes y comentárselo a Julián Besteiro, presidente de las mismas, y a Ángel Galarza, que además de diputado era el Director General de Seguridad, toda la policía de Madrid comenzó a revisar taxis en busca de la cartera perdida. Al final del día, la cartera, y su precioso contenido, apareció, pero no gracias a las pesquisas policiales, sino al taxista en cuestión, que recordando la dirección de Jiménez de Asúa, volvió a su casa al final de su jornada laboral para devolverle la cartera, y con ella, la Constitución de la II República ${ }^{58}$.

Creo que si hay una frase que puede ser una guía de la actuación de Jiménez de Asúa durante el proceso constituyente es la siguiente: "Si la República no hubiera venido para mudarlo todo, no merecería la pena haberla traído" 59 . En estas palabras se transmite la voluntad transformadora del régimen, y con ella, la necesidad de que la Constitución, con sus nuevos atributos de rigidez, garantía jurisdiccional y suprema normatividad, colmara estas esperanzas de reforma. Pero en el intento por dotar a España de una Constitución acorde a los nuevos tiempos, y en definitiva, a las nuevas necesidades, los comisionados no pusieron su vista en el derecho constitucional histórico español, inservible a estos efectos, sino que miraron a su alrededor ${ }^{60}$,

pie en el Parlamento para combatir las reformas introducidas en las sesiones matinales. He llegado al convencimiento de que me falta autoridad para presidir a ustedes y por ello le ruego que el próximo martes, 17, no falte a la reunión de las doce menos cuarto, donde presentaré la dimisión”. vid. Archivo Congreso de los Diputados (ACD), P-01-000539-0001-0001-012, pp. 1011 .

57 Manuel Azaña siempre criticó el estilo usado por Jiménez de Asúa en las Cortes. Explicaba que tenía una forma de hablar "pedantísima", la cual, con "su voz metálica y su dicción superferolítica" no hacía otra cosa que "apedrearle los sesos". vid. Manuel Azaña, Diarios completos: monarquía, república, guerra civil, Barcelona, Crítica, 2000, p. 313.

58 Luis Jiménez de Asúa, Anécdotas de las constituyentes, op. cit., pp. 68-70.

59 También la destaca, no por casualidad, Rafael Escudero Alday, Modelos de democracia en España. 1931-1978, Barcelona, Peninsula, 2013, p. 13.

60 Rafael Escudero Alday, "Las huellas del neoconstitucionalismo. Democracia, participación y justicia social en la Constitución española de 19312, en Luis I. Gordillo, Sebastián Martín y Víctor Vázquez, Constitución de 1931: estudios juridicos sobre el momento republicano español, op. cit., p. 102 . 
destacándose en este punto la Constitución de Weimar como "un punto de referencia doctrinal y práctico insoslayable para el derecho constitucional europeo continental" 61 .

La pretensión de reformar todo lo existente no impidió, como ya se ha adelantado, que se aprovechara buena parte del trabajo desarrollado por la Comisión Jurídica Asesora, así como el contenido de algunos votos particulares. En esta línea, a pesar del cambio del régimen bicameral por el unicameral que se produjo del anteproyecto al proyecto, no se dudó en reconocer que la organización de poderes recogida en el primero era merecedora de "elogios técnicos". En otros aspectos, eran muchos los elementos del anteproyecto que, si bien suponían un avance respecto del régimen constitucional que había existido hasta el momento en España, no colmaban las expectativas democráticas y progresistas, no ya de Jiménez de Asúa, sino de un electorado que había votado mayoritariamente a las izquierdas. Me refiero a aspectos tales como la concepción de la iglesia como corporación de derecho público ${ }^{62}$, el hecho de que la libertad de conciencia y religión se reconocieran desde el respeto a los concordatos con el Vaticano, que el matrimonio siguiera siendo la base de la familia o la confesionalidad de la enseñanza ${ }^{63}$. Este hecho, como se ha indicado, provocó que la comisión también tuviera en consideración los votos particulares, de donde se tomaron algunas ideas que posteriormente quedaron plasmadas en el texto del proyecto. En esta línea se puede destacar el voto particular de Francisco Romero Otazo, Manuel Pedroso, Alfonso García Valdecasas y Antonio de Luna, el cual afectó a la totalidad del Título I y trataba fundamentalmente sobre la articulación de un régimen más "federable"; el voto particular que, versando sobre el Título IV, fue firmado por Matilde Huici, Javier Elola, José Antón Oneca, Arturo Rodríguez Muñoz (ambos discípulos de Jiménez de Asúa) y José Sanchís Banús entre otros, y que planteaba la articulación de un sistema legislativo unicameral; o el voto particular que, firmado por Javier Elola y centrado en el Título IX, ampliaba las funciones del Tribunal de Justicia Constitucional, nombre con el que se recogía el Tribunal de Garantías Constitucionales en el anteproyecto ${ }^{64}$.

Desde la comisión presidida por Jiménez de Asúa se intentó romper con las restricciones del anteproyecto. El "molde nuevo" cargado de "viejo contenido" tenía que ser rellenado con las aspiraciones modernizadores del pueblo español, y los comisionados se pusieron manos a la obra con el fin de cumplir tal cometido. Así, siguiendo el análisis de Jiménez de Asúa, se dio mayor autonomía a las regiones; la parte dogmática fue más allá en cuanto al reconocimiento de derechos; la regulación de la materia religiosa fue más severa que la detallada en el anteproyecto; dejó de protegerse el matrimonio para dar cobertura a la totalidad de la familia; la propiedad estuvo sujeta a "criterios más socializantes"

61 Pablo Lucas Verdú, La lucha contra el positivismo jurídico en la República de Weimar. La teoría constitucional de Rudolf Smend, Madrid, Tecnos, 1987, p. 238.

62 Víctor Vázquez, "El legado laico de la Segunda República española”, en Luis I. Gordillo, Sebastián Martín y Víctor Vázquez, Constitución de 1931: estudios jurídicos sobre el momento republicano español, Madrid, Marcial Pons, 2017, p. 368

63 Luis Jiménez de Asúa, Proceso histórico de la Constitución de la República española, op. cit., pp. 22-24.

64 Luis Jiménez de Asúa, Proceso histórico de la Constitución de la República española, op. cit., p. 24-33. 
que los especificados en el anteproyecto; la cultura pasó a ser un elemento protegido por el Estado al garantizar la escuela única y la enseñanza laica; y la racionalización de poderes esgrimida por Mirke-Guetzevitch encontró su reflejo en un legislativo unicameral, un presidente elegido directamente por los votantes, una "justicia vigorosa" y la creación de "Consejos Técnicos"65. Jiménez de Asúa estaba plenamente convencido de que el proyecto que elaboró la comisión fue "infinitamente más armónico y esbelto qua la Constitución aprobada"66, y creía firmemente que la nueva República podría funcionar con toda normalidad bajo la sombra por él provista, pues como bien dijo en el cierre de su discurso de presentación, el proyecto presentado por la comisión era "una obra conservadora, conservadora de la República"67.

A pesar de este breve sumario de las modificaciones introducidas por la comisión respecto del anteproyecto, las próximas páginas servirán para desgranar de forma pormenorizada las novedades incluidas en el proyecto sobre las que Jiménez de Asúa tuvo especial relevancia, ya fuera por su influencia en la redacción de las mismas, o por la defensa realizada en las Cortes. Así, considero que los distintos bloques en los que puede dividirse su aportación son los siguientes: referencias nacionales y patrióticas, organización territorial, derechos y deberes, organización institucional y justicia.

\subsection{Referencias nacionales y patrióticas}

En este primer apartado pretendo recoger algunas ideas meramente simbólicas relacionadas con elementos tales como la bandera o la denominación del idioma, pero también entra en juego algo tan importante como el alcance de la nacionalidad, donde la inclinación de Jiménez de Asúa, ya surgida durante la dictadura de Primo de Rivera, por el "hispanoamericanismo"68 de corte progresista ${ }^{69}$, sería relevante, aunque bien es cierto él mismo se encargó de poner ciertos limites al reconocimiento de la doble nacionalidad.

Entrando a analizar en primer lugar estos elementos simbólicos a los que me he referido, cabe decir que el preámbulo del anteproyecto utilizaba el término "Nación española", pero en el proyecto fue cambiado por el de España. El nuevo preámbulo redactado por la comisión fue puesto en tela de juicio por algunos diputados, como fue el caso de Royo Villanova, quien, amparándose en las Constituciones de 1812, 1837 y 1869, propuso que se volviera al término originalmente usado en el anteproyecto, aunque la propuesta no llegó a buen

\footnotetext{
65 Adolfo Posada, La nouvelle constitution espagnole, op. cit., p. 114.

66 Luis Jiménez de Asúa, Proceso histórico de la Constitución de la República española, op. cit., p. XIV.

67 Diario de Sesiones de las Cortes Constituyentes, 27 de agosto de 1931, n 28, p. 648.

68 Luis Jiménez de Asúa siempre fue partidario de usar el término Hispanoamérica en lugar de Latinoamérica o Panamérica, entendía que el segundo era una construcción francesa que carecía de sentido, nunca había existido una raza latina, mientras que el segundo solo respondía a los intereses del imperialismo norteamericano. vid. "El día de la raza", FPI, ALJA 436-17, p. 6.

69 Alejado del planteamiento que concebía a las antiguas colonias españolas como hijas dependientes de la madre patria, el hispanoamericanismo progresista apostaba por el intercambio cultural e intelectual de España y las antiguas colonias en un plano de reciprocidad. vid. Luis Jiménez de Asúa, Política, Figuras, Paisajes, Madrid, Mundo Latino, 1927, p. 82
} 
puerto, pues fue desestimada por la comisión; al igual que ocurrió con la enmienda del diputado Pi i Arsauaga, defensor del término "el pueblo español"70. La comisión justificó su negativa en la sustantividad del vocablo España, defendido frente al concepto de "nación española", que consideraba algo "adjetival"71.

Otra figura de innegable carácter nacional que debe tenerse en cuenta es el de la referencia al idioma oficial de la República. Nada se había recogido al respecto en el anteproyecto, pero la comisión incluyó un artículo en el que se especificaba que "el castellano" era el idioma oficial de la República, sin perjuicio de los derechos que las leyes especiales otorgasen a determinadas regiones (en clara referencia a las regiones que pudieran alcanzar la autonomia). Varias fueron las enmiendas interpuestas, pero salvo la presentada por Miguel de Unamuno, todas fueron retiradas o desestimadas. El profesor salmantino, quien se convirtió en un referente para Jiménez de Asúa durante la dictadura de Primo de Rivera ${ }^{72}$, tras un discurso cargado de expresiones vascas e incluso de poemas en catalán y gallego, solicitó que se utilizara el término "español" en lugar de "castellano", al igual que introdujo la idea de que todos los españoles tenían la obligación de conocerlo, evitando así que desde cualquier región se impusiera el uso de otra lengua ${ }^{73}$. La comisión, tras la intervención de Jiménez de Asúa aceptó por mayoría la enmienda de Miguel de Unamuno, pero mantuvo la denominación de castellano, pues Jiménez de Asúa se encargó de alegar que el término español no era inclusivo, puesto que tanto el gallego, como el catalán y el vasco también eran españoles ${ }^{74}$.

El último elemento al que quiero hacer referencia antes de estudiar el asunto de la nacionalidad es el de la bandera tricolor. El artículo $1^{\circ}$ del proyecto exponía simplemente que España era una República democrática y que todos los poderes emanaban del pueblo; mientras que ideas como la República de trabajadores de toda clase surgieron tras debates parlamentarios en los que Jiménez de Asúa no participó. Al igual ocurrió con la constitucionalización de la bandera, que se introdujo en el texto por mediación del diputado Terrero Sánchez. Jiménez de Asúa, como se verá más adelante, fue partidario de la ampliación del campo constitucional, dando cabida a preceptos que hasta el momento habían estado fuera del ámbito abarcado por la Constitución, pero es cierto que no fue partidario de la inclusión de los colores de la bandera en el texto definitivo, tal y como expresó una vez que se negó a incluir referencias a la eugenesia: "ya es

70 Luis Jiménez de Asúa, Proceso histórico de la Constitución de la República española, op. cit., p. 108 .

71 Nicolás Pérez Serrano, La Constitución española. Antecedentes, textos, comentarios, op. cit., pp. 48-49.

72 A pesar de que Jiménez de Asúa y Miguel de Unamuno se erigieran como los grandes opositores a la dictadura dentro del mundo universitario, el primero siempre sintió devoción por el filósofo, a quien se dirigía como maestro. vid. Icíar Fernández Marrón, "Cartas de cuatro juristas republicanos a Miguel de Unamuno (1920-1936)", en Cuadernos de la Cátedra Miguel de Unamuno, $\mathrm{n}^{\circ} 33,1998$, p. 203.

${ }^{73}$ Diario de Sesiones de las Cortes Constituyentes, 18 de septiembre de $1931, n^{\circ} 41$, pp. 10151020.

${ }^{74}$ Luis Jiménez de Asúa, Proceso histórico de la Constitución de la República española, op. cit., p. $113-114$. 
bastante que se haya traído el percal de la bandera"75. No obstante, tanto el cambio de bandera mediante decreto el día 27 de abril, como su inclusión en la Constitución levantó grandes quejas ${ }^{76}$, al igual que ocurrió en Alemania tras la instauración de la República de Weimar ${ }^{77}$.

Finalmente, en lo referente a la nacionalidad, cabría pensar que el hispanoamericanismo progresista propugnado por Jiménez de Asúa desde la dictadura de Primo de Rivera lo empujó al reconocimiento total de la doble nacionalidad de los habitantes de las antiguas colonias tanto españolas como portuguesas $^{78}$, pero lo cierto es que el contenido plasmado en el proyecto, $\mathrm{y}$ posteriormente en la Constitución, fue distinto al que podría esperarse. Jiménez de Asúa entendió que el reconocimiento de la doble nacionalidad sin ningún tipo de limitación podría suponer "problemas insolubles en el derecho", de manera que lo condicionó a que los países en cuestión también reconocieran la doble nacionalidad, lo que si "supondría una ventaja inmensa para el hispanoamericanismo"79. No obstante, la inclinación de Jiménez de Asúa por la concesión de la doble nacionalidad en el mero caso de reciprocidad no fue uno de sus aportes directos a la Constitución, sino que ya venía reflejada en el anteproyecto y en un voto particular de Manuel Pedroso ${ }^{80}$, quien, de cualquier modo, formaba parte del que podriamos denominar como "intelectual colectivo" crítico con el sistema de la Restauración y la dictadura, del cual también tomaba cuota el propio Asúa. No deja, sin embargo, de ser llamativo cómo tras una férrea defensa de un hispanoamericanismo amplio y progresista (en clara contraposición con la postura oficial de la dictadura de Primo de Rivera), prefirió no plasmarlo en el proyecto constitucional en pos de la defensa del derecho. Es más, fueron varias las asociaciones que se dirigieron a las Cortes Constituyentes con el objetivo de exigir la doble nacionalidad. Tal fue el caso de la Liga Prohispanoamérica, pues en las naciones en las que se luchaba "por implantar la ciudadanía hispanoamericana soñada por Bolivar (...) el proyecto de Constitución redactado por la comisión ha[bia] causado un efecto deplorable"81. Y cabe también destacarse el caso del Centro Israelita Agudad "Ahim", quienes pedían la nacionalidad para los sefarditas, que eran "súbditos españoles injustamente 65.

75 Nicolás Pérez Serrano, La Constitución española. Antecedentes, textos, comentarios, op. cit., p.

76 Es curiosa la insistencia de la Asociación Patriótica Española de Buenos Aires, la cual envió numerosos documentos a las Cortes, rogando que no se modificara la bandera, pues era "tan sagrado ese símbolo de la patria, que nadie t[enía] derecho a cambiarlo". vid. Archivo del Congreso de los Diputados, P-01-000539-0001-0006-001, p. 2-3.

77 Nicolás Pérez Serrano, La Constitución española. Antecedentes, textos, comentarios, op. cit., p. 64.

78 En su concepción de Hispanoamérica tenian cabida los territorios que pertenecieron tanto al Imperio español como al portugués. vid. Enrique Roldán Cañizares, Derecho penal, República, exilio, Madrid, Dykinson, 2019, p. 163.

79 Diario de Sesiones de las Cortes Constituyentes, 27 de agosto de 1931, nº 28, p. 645. 113.

80 Nicolás Pérez Serrano, La Constitución española. Antecedentes, textos, comentarios, op. cit., p.

81 Archivo del Congreso de los Diputados, P-01-000539-0001-0001-016, p. 2. 
despojados de su nacionalidad"82; una posibilidad que, realmente, nunca llegó a estar sobre la mesa.

\subsection{Organización territorial}

Al enumerar los problemas que, según Jiménez de Asúa, la República debía afrontar, hice mención a la idea que pedía alcanzar una transacción entre la unidad de España y la mayor autonomía de las regiones que así lo desearan. De hecho, siguiendo esta línea, no dudó en asegurar que era "demasiado liberal para mantener bajo [su] destino a quien dese[ase] ensayar el vuelo independiente" y que "siendo castellano jamás [se] negaría a dar libertad a quien se cre[yese] oprimido" 83 . Partiendo de esta base, y teniendo en cuenta que el Estatuto de Cataluña se presentó cuatro días antes de que el proyecto se hiciera público, Jiménez de Asúa se cuidó de alcanzar una organización que, sin atacar a la indisolubilidad de España, permitiera la autonomía de Cataluña y de aquellas regiones que así lo desearan. De este modo, el propio Nicolás Pérez Serrano advirtió que el Estatuto catalán influyó constantemente durante la elaboración y tramitación del proyecto ${ }^{84}$. Pero entiendo que no fue el mero hecho de la existencia de un Estatuto la razón que llevó a Jiménez de Asúa a buscar un punto de encuentro entre las pretensiones catalanas y castellanas, pues ya desde el año 1930, cuando visitó Cataluña junto con un grupo de intelectuales españoles, mostró un gran interés en comprender y encontrar una solución para el problema catalán ${ }^{85}$.

Obviando el anteproyecto, que partía de la base de que la gran mayoría del país no protestaba contra la organización territorial preexistente ni anhelaba una nueva ${ }^{86}$, así como el voto particular de Romero Otazo, Manuel Pedroso, García Valdecasas y Antonio de Luna, que proponía un sistema en el que el Estado delegaba competencias en los territorios autónomos (no obstante, Albacete Ezcurra defiende que este voto particular fue la inspiración principal de la fórmula del Estado integral) ${ }^{87}$, la comisión trajo a colación un planteamiento completamente nuevo en la historia del constitucionalismo español: el Estado "integral"88. Jiménez de Asúa quería huir del unitarismo y el federalismo, pues

\footnotetext{
82 Archivo del Congreso de los Diputados, P-01-000539-0001-0001-016, p. 3.

83 Luis Jiménez de Asúa, La Constitución de la democracia española y el problema regional, op. cit., p. 86-87.

${ }^{84}$ Nicolás Pérez Serrano, La Constitución española. Antecedentes, textos, comentarios, op. cit., p.
} 77.

85 Luis Jiménez de Asúa, La Constitución de la democracia española y el problema regional, op. cit., p. 87-91.

86 Andrés de Blas Guerrero, "El debate doctrinal sobre la autonomía en las constituyentes de la II República", Historia contemporánea, n 6, 1991, pp. 119-144.

87 Juan Enrique Albacete Ezcurra, El Estado integral de la Segunda República española, Murcia, Nausicaa, 2006, p. 341.

88 Tomás y Valiente explicó que no era de extrañar que en un contexto en el que jóvenes profesores españoles habian ampliado sus conocimientos en ciudades como Berlín (como fue el caso de Jiménez de Asúa) Viena o Friburgo, la Comisión parlamentaria se apoyara en una idea de raigambre germana. Vid. Francisco Tomás y Valiente, "El Estado Integral: nacimiento y virtualidad de una fórmula poco estudiada”, en Obras Completas, III, Madrid, Centro de Estudios Politicos y Constitucionales, 1997, p. 2049. 
entendia que ambos términos estaban en franca decadencia. El unitarismo habia demostrado su ineficacia durante la dictadura de Primo de Rivera, mientras que el federalismo no era pertinente en España puesto que, para Jiménez de Asúa, federar era sinónimo de unir piezas o entidades separadas, de manera que era imposible federar lo que ya estaba unido. La idea, por lo tanto, era "establecer un gran Estado Integral en el que [fueran] compatibles, junto a la gran España, las regiones". Un planteamiento que enlaza con la concepción defendida por Jiménez de Asúa de que el socialismo, más que una ideología política, era una civilización: "El socialismo tiende a grandes sintesis, el socialismo quisiera hacer del mundo entero un Estado de proporciones mayúsculas: la federación de Europa y aun del mundo sería su aspiración más legitima. Somos nosotros, los socialistas, no un partido, sino una civilización, y precisamente eso nos ha hecho pensar en el Estado integral y no en el Estado federal; y por lo mismo que somos una civilización, no podemos, no podemos desconocer que las regiones tienen su derecho a vivir autónomas cuando así lo quieran"89.

De hecho, Sebastián Martín ilustra el uso del concepto "integral" por parte de diferentes posiciones ideológicas (no en vano fue utilizado desde posturas totalitarias) tras la elaboración de la teoría de la integración por parte de Rudolf Smend. En un contexto en el que la circulación de los términos "integral", "integrado" o "integrante" fueron ampliamente utilizados en el ámbito jurídicopolítico (hasta el punto de darse un uso del término de carácter transversal, llegando a abarcar incluso a las derechas fascistas), en el caso español fue el socialismo el que se apoyó en ellos para construir sus planteamientos revolucionarios ${ }^{90}$. Pero tras la elección de este sistema cabe preguntarse de dónde surgió la idea del Estado integral, cuya denominación y definición, que finalmente se incluyó en el artículo $1^{\circ}$ de la Constitución española, ni siquiera aparecía en el proyecto $^{91}$ a pesar de que su gran impulsor fuera Jiménez de Asúa. A lo largo de la presentación del proyecto en las Cortes, éste explicó que fue Hugo Preuss quien, "con su gran mente poderosa y elegante", fijó las doctrinas del Estado integral $^{92}$ (a pesar de que Nicolás Pérez Serrano atribuyera su defensa en España a Miguel Cuevas ${ }^{93}$, a quien, no se debe olvidar, Jiménez de Asúa recordó por su ayuda indispensable en la obtención de lecturas relativas al derecho constitucional). En esta línea, Giacomo Demarchi ha presentado el Estado integral como una creación de Hugo Preuss para poner coto al dominio conservador de Prusia, y con más profundidad, como una solución en los últimos años de la República de Weimar al problema entre soberanía y autonomía en el contexto de la relación entre Estado y territorios ${ }^{94}$, un enfoque que encaja

89 Diario de Sesiones de las Cortes Constituyentes, 27 de agosto de 1931, n 28, p. 645.

90 Sebastián Martín, "Lecturas de la Integrationslehre de Rudolf Smend en la doctrina jurídicopolitica española de los años treinta", Revista de estudios políticos, n 82, 2018, pp. 99-128.

91 Joaquín Varela Suanzes-Carpegna, "La Constitución de 1931 y la organización territorial del Estado", Iura Vasconiae, n ${ }^{\circ} 10,2013$, pp. 323-354.

92 Diario de Sesiones de las Cortes Constituyentes, 27 de agosto de 1931, n 28, p. 645.

93 Nicolás Pérez Serrano, La Constitución española. Antecedentes, textos, comentarios, op. cit., pp. 32-63.

94 Giacomo Demarchi, Provincia y territorio en la constituyente española de 1931, Madrid, Dykinson, 2016, pp. 216-217. 
perfectamente con la solución que Jiménez de Asúa buscaba para el problema territorial español.

Pero lo cierto es que a día de hoy sigue sin estar clara la paternidad científica, al menos en España, de la idea del Estado integral. En este sentido es de gran ayuda el trabajo de Daniel Guerra Sesma, quien recoge la gran variedad de posibilidades existentes. Desde el planteamiento de Albacete Ezcurra, quien se la atribuye a Adolfo Posada sobre la base de los trabajos de Hugo Preuss (una aseveración dudosa teniendo en cuenta la cercaría entre Posada y Pérez Serrano y la ausencia de referencia de este tipo en los trabajos del segundo); hasta el planteamiento de Tomás y Valiente, quien se lo atribuyó a Francisco Ayala (muy cercano en este periodo a Jiménez de Asúa), a pesar de que indicara que previamente lo había utilizado Rudolf Smend; pasando por el caso ya citado de Nicolás Pérez Serrano, quien se lo atribuía a Miguel Cuevas ${ }^{95}$. Independientemente del origen científico del término, Jiménez de Asúa fue su impulsor politico y su gran defensor dentro de las Cortes Constituyentes, y como él mismo alegó en los diarios españoles, no lo hizo por ser regionalista o catalanista $^{96}$, sino por tener el más vivo interés en solucionar el problema catalán y alcanzar una España que, en la comprensión de sus diferencias, pudiera avanzar al unísono. Como bien ha apuntado Sebastián Martín, el Estado Integral entroncaba perfectamente con el esfuerzo de síntesis y superación de la bipolaridad por parte los juristas republicanos. Así, el novedoso sistema territorial fue concebido como un "tercer modelo" que conciliaba la unidad de la soberanía del Estado y la autonomía política de las regiones ${ }^{97}$.

\subsection{Derechos y deberes}

La estructura de la parte dogmática de la Constitución partió de la organización seguida por la Constitución de Weimar, la cual separó en dos grupos la declaración de derechos, uno centrado en la esfera individual y politica y otro en el orden económico y cultural ${ }^{98}$. En lo relativo a la mera existencia de la declaración, el propio Jiménez de Asúa dejó claro que su inclusión en la Constitución no era necesaria, como bien había demostrado el constitucionalismo histórico (Constitución francesa de 1875) y el comparado (Constitución austriaca de 1920). No obstante, consideró que la parte dogmática era "tan importante o más que la orgánica"99, de ahí que pasara a formar parte del texto republicano. La necesidad de ampliar el elenco de derechos y dotarlos de verdaderas garantias para que pasara de ser una mera "declamación"100 a una auténtica declaración,

95 Daniel Guerra Sesma, "El modelo territorial de las izquierdas en la Segunda República", Luis I. Gordillo, Sebastián Martín y Victor Vázquez, Constitución de 1931: estudios jurídicos sobre el momento republicano español, op. cit., p. 186.

96 Luis Jiménez de Asúa, “Constitución española y Estatuto catalán”, La Libertad, 29 de septiembre de 1931, pp. 1-2.

97 Sebastián Martín, Entre Weimar y Franco, Granada, Comares, 2017, p. 367.

98 Joan Oliver Araujo, "La Constitución republicana de 1931", Dereito: revista xuridica da Universidade de Santiago de Compostela, vol. 6, n 1, 1997, pp. 107-119.

99 Diario de Sesiones de las Cortes Constituyentes, 27 de agosto de 1931, n 28, p. 645.

100 Luis Jiménez de Asúa, Proceso histórico de la Constitución de la República española, op. cit., p. 65 . 
se enmarcaba en la necesidad de llevar al texto constitucional, no solo los derechos tradicionalmente reconocidos, sino también los anhelos y las esperanzas del pueblo101. Este hecho, empero, de ningún modo se trató de una originalidad del caso español, sino que estaba presente en las constituciones del periodo de entreguerras tales como la de la U.R.S.S. o la de Weimar, donde el elenco de derechos se amplió en función de los nuevos problemas que sus respectivas sociedades debían afrontar ${ }^{102}$.

En el análisis de los derechos reconocidos en la parte dogmática de la Constitución no voy a hacer mención a aquellos artículos centrados en la cuestión religiosa, pues su importancia fue tal en el proceso constituyente y en el devenir de la propia República que entiendo que merecen un estudio separado. De igual modo, aquellos relacionados con la justicia, tales como el reconocimiento del principio de legalidad, serán repasados en un apartado dedicado integramente a los aspectos judiciales, una separación que entiendo que es justa, teniendo en cuenta la dedicación de Jiménez de Asúa al derecho penal, tanto en el ámbito profesional como en el académico. Y otros ámbitos novedosos, como fue la regulación del trabajo asalariado (no en vano la Constitución de 1931 fue la primera Constitución española que lo incluyó en su articulado) ${ }^{103}$, van a quedar fuera del estudio por la escasa implicación de Jiménez de Asúa en su elaboración y discusión. Así, sin ser necesario entrar en el estudio de derechos tradicionalmente reconocidos, tales como la libertad de circulación, el derecho de petición o la libertad de expresión o reunión, quiero centrarme en la igualdad de derechos en los dos sexos, y su conexión con los derechos electorales, la regulación de la familia y el divorcio y la regulación de la propiedad.

En las múltiples disertaciones realizadas durante la dictadura de Primo de Rivera, contexto en el que Jiménez de Asúa comenzó a alcanzar relevancia pública, la situación de las mujeres en la sociedad y la lucha por alcanzar la igualdad entre ambos sexos fue uno de los temas en los que, alejado del derecho penal, Jiménez de Asúa profundizó. De sus palabras se deslizaba la necesidad de empoderamiento de la mujer y lo importante que sería para la sociedad que las mujeres jóvenes dieran un paso al frente y se sacudieran las reminiscencias católicas y conservadoras que provocaban que no pudieran contribuir efectivamente al avance de la sociedad ${ }^{104}$. De este planteamiento se deducen dos razonamientos: el primero es la necesidad de que la mujer participara en la vida pública y saliera del hogar para competir en pie de igualdad con el hombre, pero el segundo es la pervivencia de la mujer conservadora que, encargada de educar a sus hijos, ponía límites a la evolución de la conciencia pública, y, por ende, al avance social ${ }^{105}$. Teniendo en cuenta este razonamiento, y, en definitiva, este

101 Diario de Sesiones de las Cortes Constituyentes, 27 de agosto de 1931, n 28, p. 643.

102 Francisco Javier Corcuera Atienza, "La Constitución española de 1931 en la historia constitucional comparada", Fundamentos: cuadernos monográficos de teoría del estado, derecho público e historia constitucional, n² 2, 2000, pp. 629-695.

103 Joaquín López Rey, "La Constitución del trabajo en la Segunda República española”, Luis I. Gordillo, Sebastián Martín y Víctor Vázquez, Constitución de 1931: estudios juridicos sobre el momento republicano español, op. cit., p. 322.

104 Luis Jiménez de Asúa. Juventud, op. cit., pp. 81-88.

105 Llegó a exponer el caso de políticos de izquierdas que, al tener mujeres conservadoras y católicas, terminaban teniendo hijos muy alejados del espectro político del padre, no consiguiente 
miedo a la involución que pudiera suponer la influencia de las mujeres conservadoras y católicas, se entiende que, desde su cargo de presidente de la comisión, no cambiara ni una coma a la frase del anteproyecto que reconocía "en principio, la igualdad de derechos de los dos sexos". Esa permanencia de "en principio", es la muestra inequivoca de que los recelos planteados durante la dictadura de Primo de Rivera seguían vigentes en el Jiménez de Asúa constitucionalista. No obstante, la discusión parlamentaria y en concreto la intervención de Clara Campoamor, produjo "un triunfo del feminismo"106 y la eliminación del desdichado "en principio", para dar paso a la igualdad formal absoluta en razón del sexo.

En conexión directa con la igualdad de sexos apareció la igualdad de derecho electoral para hombres y mujeres mayores de 23 años. No se trató de una aportación novedosa de la comisión, pues ya se encontraba presente en el anteproyecto, sin embargo, los debates en el parlamento fueron enconados. Eran pocos los diputados que rechazaban el voto femenino, pero entre muchos cundia el miedo a que tuviera efectos negativos para el futuro de la II República. Finalmente, el artículo fue aprobado por 161 votos a favor (entre los que se incluyeron los de la minoría socialista) y 121 en contra, convirtiéndose España en el primer país hispanoamericano que conquistó la igualdad en derechos electorales ${ }^{107}$. Jiménez de Asúa, por sometimiento a la disciplina de partido, votó favorablemente a la inclusión en la Constitución del reconocimiento del voto femenino, pero con el paso de los años dio muestras de arrepentimiento. Así, en el año 1940, cuando encontró en el exilio argentino la única salida a la España franquista, aseguró que el triunfo formal de las derechas en las elecciones de la segunda legislatura republicana, se debió en buena parte al voto femenino ${ }^{108}$. Tres años más tarde, lejos de arrepentirse de lo dicho en 1940, aseguró que habría sido conveniente esperar un poco más de tiempo para la implantación del voto femenino, pues "hacer dos revoluciones al mismo tiempo" tuvo consecuencias catastróficas para la República ${ }^{109}$.

La introducción del divorcio en el contexto de la regulación constitucional de la familia fue otro de los elementos novedosos incluidos por el trabajo de la comisión, pues nada se decía al respecto en el anteproyecto. Como bien recuerda Alfons Aragoneses, Demófilo de Buen apuntó que con los artículos 25 (prohibición de privilegios jurídicos) y 43 (regulación de la familia), la Constitución había "logrado demoler las paredes maestras del derecho de familia

por lo tanto que las nuevas generaciones avanzasen y fuesen conscientes de la importancia de luchar por el cambio social. Vid. Luis Jiménez de Asúa. Juventud, op. cit., pp. 89-97.

106 Nicolás Pérez Serrano, La Constitución española. Antecedentes, textos, comentarios, op. cit., p. 128.

107 Alicia López de los Mozos, "Igualdad de género en la Segunda República”, en Luis I. Gordillo, Sebastián Martín y Víctor Vázquez, Constitución de 1931: estudios jurídicos sobre el momento republicano español, op. cit., p. 356.

108 Luis Jiménez de Asúa, La Constitución de la democracia española y el problema regional, op. cit., pp. 34-35.

109 “Conferencia sustentada por el doctor Luis Jiménez de Asúa, en la Sala de conferencias del palacio de las Bellas Artes la noche del 10 de febrero de 1943, organizada por Acción Democrática Internacional", FPI, ALJA 435-1, p. 11. 
contenido en [el] código civil"110. Si bien el texto constitucional definitivo recogía la posibilidad de divorcio "por mutuo disenso o a petición de cualquiera de los cónyuges, con alegación en este caso de justa causa", el proyecto de la comisión recogía la posibilidad de disolución del matrimonio por libre voluntad de la mujer, mientras que el marido sí se vería obligado a alegar justa causa. Esta fórmula fue redactada por Jiménez de Asúa, quien se basó en la Ley de divorcio de Uruguay y, según el propio autor, se alejaba de cualquier "audacia feminista". Al contrario, entendia que se trataba de una medida de "prudente conservadurismo" que justificaba de la siguiente forma: ante la lógica de no objetar nada al divorcio por mutuo disenso, el divorcio solicitado por parte del marido debía estar justificado ante el peligro de que éste, en una actitud donjuanesca111, aprovechara el divorcio para convertirse en un "catador de mujeres". Sin embargo, en el caso de la mujer, para quien el matrimonio seguía siendo en muchos casos la "auténtica carrera femenina", no era necesario incluir limitaciones, pues solo en casos muy graves las mujeres serian capaces de dar el paso y pedir el divorcio a sus parejas $^{112}$.

Hay otro aspecto que debe tenerse en cuenta en relación al ámbito familiar. Más allá de que se erigiera la familia, y no el matrimonio, como el elemento a salvaguardar por el Estado (idea que fue tomada de la Constitución de Weimar y que también fue incluida por los trabajos de la comisión) ${ }^{113}$, la otra nota determinante fue la igualdad de hijos tenidos dentro y fuera del matrimonio, algo impensable hasta el momento tanto en el derecho civil como en el derecho constitucional español. De hecho, en este sentido es curioso destacar una carta recibida por Jiménez de Asúa el 16 de agosto de 1931, cuando todavía se hallaba inmerso en los trabajos de la comisión, en la que el tarraconense Basilio Gómez del Campo le pedía, en su cargo de presidente de la comisión, que se recogiera constitucionalmente la igualdad de hijos llamados entonces "ilegitimos". E1 atrevido catalán había estado casado bastantes años, pero durante el matrimonio tuvo tres hijos con otra persona. Sus hijos, obviamente, no pudieron tomar su apellido, y mientras estuvo casado nada pudo hacer al respecto. Sin embargo, su mujer murió al poco tiempo de proclamarse la República, de manera que escribió para solicitar la igualdad, pues nada le hacía más ilusión que poder darles su apellido a sus tres descendientes ${ }^{114}$. Nada se sabe de la respuesta de Jiménez de Asúa y de la posible influencia de la carta de tan promiscuo personaje, pero bien podría ser una muestra de la vieja máxima Saepissime leges oriuntur ex causis recogida por Leovigildo en Liber iudiciorum 5.4.17 antiqua: los problemas concretos están en el origen de las leyes.

110 Alfons Aragoneses, "Constitución y derecho civil en la Segunda República", en Luis I. Gordillo, Sebastián Martín y Victor Vázquez, Constitución de 1931: estudios juridicos sobre el momento republicano español, op. cit., p. 269.

111 En sus escritos sobre eugenesia y libertad de amor, Jiménez de Asúa apuntó que la lucha contra el donjuanismo de los españoles era fundamental para un mejor desarrollo de la sociedad. Vid. Luis Jiménez de Asúa, Libertad de amar y derecho a morir, Madrid, Historia nueva, 1928, p. 6.

112 Luis Jiménez de Asúa, Proceso histórico de la Constitución de la República española, op. cit., pp. 275-276.

113 Nicolás Pérez Serrano, La Constitución española. Antecedentes, textos, comentarios, op. cit., p. 185.

114 Archivo del Congreso de los Diputados, P-01-000539-0001-0001-016, pp. 11-14. 
Finalmente quiero poner el foco en la regulación constitucional que se hizo de la propiedad, durante cuya discusión Jiménez de Asúa llegó a presentar su dimisión. Antes de llegar a ese punto, es necesario remontarse al discurso de presentación del proyecto parlamentario, donde dijo con acierto que el proyecto de Constitución que se presentaba no era socialista (pues se reconocía el derecho de propiedad privada), pero sí de izquierdas ${ }^{115}$. La calificación del anteproyecto como "retardatario, reaccionario y confuso"116 cobraba sentido en el modo de dar cobijo a la propiedad, pues en ningún momento se tomó en consideración el empuje de las fuerzas defensoras de la socialización que, tanto en España como en el resto de Europa, eran una obviedad, y habian tenido repercusión en las constituciones de entreguerras ${ }^{117}$. El proyecto, sin embargo, decía que el Estado reconocía "actualmente la propiedad privada en razón directa de la función útil que en ella desempeña[ra] el propietario". Obsérvese que la introducción de la palabra "actualmente" ponía en tela de juicio el concepto de propiedad burguesa como derecho natural ${ }^{118}$, al mismo tiempo que denotaba una concepción de la II República, por parte de los comisionados, como un periodo de transición hacia el socialismo119, en el cual también tenía cabida la "procedencia de expropiación sin indemnización" y "la nacionalización de los servicios públicos y las explotaciones que afecta[ran] al interés nacional". En la redacción final, una vez que se aceptaron enmiendas surgidas del debate parlamentario, fue eliminada la palabra "actualmente", pero mantuvo la posibilidad de que, mediante ley aprobada por mayoria absoluta, tuviera cabida la expropiación sin indemnización (con un antecedente similar en la Constitución de Weimar ${ }^{120}$ ) y la posible nacionalización de los servicios públicos y explotaciones que afectaran a la utilidad social.

Para concluir el estudio de la temática relacionada con la propiedad es necesario volver atrás y fijar la vista en la dimisión que Jiménez de Asúa llegó a presentar, la cual, si bien no tuvo absolutamente nada que ver con la idea de propiedad, si llegó en el contexto de su discusión. En varias ocasiones, los diferentes miembros de la comisión comentaron la "copiosa e indebida actividad de Alcalá-Zamora", quien, según éstos, siempre se veía obligado a dar un discurso o verter su opinión sobre el artículo en torno al cual versara la discusión. Esta postura, que con el paso del tiempo Jiménez de Asúa comprendió como expresión de ánimo conciliador y transaccional, llegó a excitar los ánimos de la comisión, hasta el punto que el comisionado Juan Botella, quien fue encargado de defender la propuesta de la comisión en relación con la propiedad, estalló ante las continuas intervenciones de Alcalá-Zamora, reprochándole su "incontinencia oratoria". Ante aquella salida de tono, la relativa paz y estabilidad

115 Diario de Sesiones de las Cortes Constituyentes, 27 de agosto de 1931, n 28, p. 648.

116 Javier Infante, "Un hito en la historia constitucional de España: el derecho de propiedad", op. cit., p. 303.

117 Javier Corcuera Atienza, "El constitucionalismo de entreguerras y la Constitución española de 1931", op. cit., pp. 15-46

118 Luis Garrido González, "Constitución y reformas socioeconómicas en la España de la II República”, Historia contemporánea, n 6, 1991, p. 173-190.

119 Tal era la noción sostenida por Jiménez de Asúa, según procuro mostrar en Enrique Roldán Cañizares, Luis Jiménez de Asúa: Derecho penal, República, exilio, op. cit., pp. 191-193.

120 Sebastián Martín, "Lecturas de la Integrationslehre de Rudolf Smend en la doctrina jurídicopolitica española de los años treinta", op. cit., pp. 99-128. 
que había reinado hasta el momento en la comisión saltó por los aires, produciéndose reproches y dimisiones entre aquellos miembros que, por pertenencia al mismo partido, como fue el caso de Castrillo, o por creer que Alcalá-Zamora defendía sus intereses, como ocurrió con el autonomista catalán Antonio Xirau, no toleraron las palabras de Botella. Jiménez de Asúa, quien reconoce que hubo de terciar, "incluso fisicamente", para que los diputados no llegaran a las manos, consiguió que, en una reunión privada de la comisión, ésta decidiera hacer un comunicado en el que se reconocía que el señor Botella, en su crítica a Alcalá-Zamora, había actuado en nombre de la comisión, y que aquellos comisionados que habian mostrado sus discrepancias, lo hicieron a título personal.

Las palabras de Jiménez de Asúa sobre la reacción de Alcalá-Zamora son bastante esclarecedoras: "volvió su ceniciento rostro hacia mí; los ojos giraron furiosamente en las órbitas, y con una mueca, muy suya, dejó caer la mandíbula inferior, como se desencaja la de los cadáveres". En su discurso, en el que terminó dimitiendo de la presidencia del consejo de ministros, se declaró incompatible con Jiménez de Asía, quien había actuado, a ojos del todavía presidente, con "premeditación, alevosía y nocturnidad"121. Jiménez de Asúa tomó la palabra para alegar que la comisión había decidido no entrar en el fondo del asunto y limitarse a declararse en solidaridad con Botella, pues era lógico y evidente que había hablado en nombre de la comisión y que Castrillo y Xirau lo habían desautorizado públicamente. Herido por las acusaciones de AlcaláZamora, aprovechó para recordar los grandes sacrificios personales que para él había supuesto aceptar la presidencia de la comisión, pero al mismo tiempo no dudó en dejar claro que las imputaciones de Alcalá-Zamora le habían dado libre para presentar la dimisión:

"Cuando el incidente de esta tarde, que no es preciso recordar, terminó con la suspensión de la sesión, se encontraba la comisión con profundas divisiones. El señor Botella había dimitido; el señor Samper me anunció de la misma manera su dimisión; el señor Castrillo pensaba al unísono, y yo, que he venido haciendo los mayores sacrificios para conservar unida una Comisión de este tipo, en la que están representados todos los partidos y cuya heterogeneidad es patente, creí inexcusable el procurar soldarla (...) No hemos querido entrar en el fondo del suceso, y así lo declaramos de una manera terminante en la nota (...) y que tan solo nos hacemos solidarios del señor Botella en cuanto defendía el dictamen (...) $\mathrm{Y}$ ahora es absolutamente inexcusable que yo recoja alusiones directas del señor Alcalá-Zamora (...) Me he sacrificado por entender que ser presidente de una comisión quita toda iniciativa y corta todo juicio personal; he hablado, en suma, solo como presidente de la comisión, pero he de decir que las imputaciones del señor Alcalá-Zamora me dan la coyuntura para dejar a salvo la comisión, y voy a copiar ahora uno de los rasgos más elegantes que, como maestro político de todos, ha demostrado el señor presidente del Gobierno; yo también he formado con la comisión de constitución una sociedad en que las ganancias son todas para ella, y las pérdidas para mí; y yo, que no he puesto una palabra siquiera en el papel que aquí he leído, que no es de mi pluma ni mi iniciativa en absoluto, ya que no he hecho más que presidir la sesión para poner orden en medio de las luchas y discrepancias que surgian, yo me hago responsable ahora de lo que no

121 Luis Jiménez de Asúa, Anécdotas de las Constituyentes, op. cit., pp. 47-53. 
hice y de lo que, en el fondo, tal vez no esté de acuerdo con mi pensamiento, para presentar en plena Cámara la dimisión de mi cargo de presidente de comisión de Constitución." 122 .

En el momento en el que fue llamado a consulta por Julián Besteiro en su cargo de presidente de las Cortes dejó claro que su dimisión había tenido lugar como un medio para evitar que Alcalá-Zamora siguiera adelante con la suya, pues entendia que "una crisis de Gabinete era mil veces más grave que [su] renuncia". Estas actuaciones de Alcalá-Zamora y de Jiménez de Asúa, que sin duda se enmarcan en la grandilocuencia y el simbolismo de las discusiones que se dieron entre los intelectuales que daban vida al Parlamento, concluyó con la retirada de ambas dimisiones y con la vuelta de Alcalá-Zamora a su asiento, quien, "como los hombres obesos en demasia, que en los tiempos en que no hubo ascensores tenían que subir al cuarto piso por etapas, reposando en cada descansillo, (...) regresó al eminente sitio por grados: en la cola, primero; al medio, después, y por fin, en la presidencia"123.

\subsection{Organización institucional}

No cabe duda de que el parlamentarismo fue la punta de lanza de la organización institucional del proyecto presentado por la comisión. No podía ser de otro modo, pues al mismo tiempo que se seguía la filosofia de las constituciones de entreguerras ${ }^{124}$, los prohombres de la República eran poseedores de una vocación parlamentaria y oratoria que no daba lugar a otra posibilidad $^{125}$. Además, toda la oposición a la monarquía y la dictadura se había consustanciado en una reivindicación del parlamento, que o bien no fue más que títere decorativo y subalterno, o bien, ya en la dictadura, fue institución suspendida. No obstante, en el proyecto encabezado por Jiménez de Asúa se incluyeron algunos elementos que ponían coto a un parlamentarismo desbocado, relativos en su mayoría a las competencias del presidente de la República y a la creación de consejos técnicos. Estos últimos estuvieron inspirados en los ya existentes en Alemania, Irlanda o Yugoslavia, y eran concebidos por Jiménez de Asúa como un contrapeso a la cámara única, al contar con ciertas capacidades en lo relativo a la preparación de proyectos legislativos ${ }^{126}$, pero finalmente, el Parlamento rechazó su inclusión en la Constitución ${ }^{127}$.

122 Diario de Sesiones de las Cortes constituyentes, 6 de octubre de 1931, $\mathrm{n}^{\circ}$ 50, pp. 14721473.

123 Luis Jiménez de Asúa, Anécdotas de las Constituyentes, op. cit., p. 59.

124 Rafael Escudero Alday, “Las huellas del neoconstitucionalismo”, op. cit., p. 101.

125 Miguel Ángel Giménez Martínez, "El régimen parlamentario de la Segunda República y las relaciones entre su presidente, el Gobierno y las Cortes", Hispania nova: revista de historia contemporánea, $\mathrm{n}^{\circ}$ 13, 2015, pp. 54-77.

126 Juan Oliver Araujo, "Las Cortes en la Segunda República española: luces y sombras 85 años después", Revista de derecho politico, n 102, 2018, pp. 15-46.

127 Jiménez de Asúa achacó el rechazo del parlamento a un "error de táctica". Fernando de los Ríos, entonces ministro de Justicia, se reveló como uno de los más fervientes defensores de la creación de los Consejos técnicos. Sin embargo, cuando se presentó una enmienda pidiendo su supresión, la minoría socialista no la tomó en importancia, sin encomendar su defensa a de los Ríos. Para sorpresa de Jiménez de Asúa, la enmienda que apostaba por la supresión fue aprobada por mayoría, de manera que cuando de los Ríos habló de lo importante que habría sido la 
La novedad más significativa, más allá de que en el proyecto figurara el nombre Parlamento, en lugar de Cortes, fue la inclusión de un sistema unicameral, el cual no se daba en España desde la Constitución de 1812. El anteproyecto de la Comisión Jurídica Asesora recogía un sistema bicameral, aunque bien es cierto que un voto particular de Matilde Huici, Manuel Pedroso y José Antón Oneca entre otros se planteaba la necesidad de contar con una sola cámara ${ }^{128}$. Para defender la supresión del Senado Jiménez de Asúa recurrió a Sieyes: "Si las dos cámaras van unidas y representan la voluntad popular, una sobra; si la otra se opone, entonces no representa la "volonté générale", que es lo que debe representar el poder legislativo". Entendía que resucitar el Senado era volver a dar cabida dentro de las instituciones democráticas a las diferencias por edad, cultura y riqueza, algo expresamente excluido por el constitucionalismo republicano ${ }^{129}$. Y asi lo entendió también la mayoría del parlamento, que votó por 150 votos contra 100 la existencia de una sola cámara130.

El otro componente de la organización institucional que planteó el proyecto de forma novedosa respecto de lo recogido del anteproyecto fue la elección del presidente de la República; aunque bien es cierto que el resto del articulado fue aprovechado en su práctica totalidad, sin ni siquiera llegar a corregir, según Pérez Serrano, el orden "poco sistemático de (...) los preceptos"131. Jiménez de Asúa había apostado por una elección del Presidente de la República a través del "sufragio universal, igual, directo y secreto". Su idea era encontrar un punto medio entre una presidencia fuerte y una débil. Por esa razón planteó la necesidad de que el Presidente no fuera elegido por ninguna comisión o consejo, sino que apostó una elección directa por el pueblo (siguiendo el ejemplo de Weimar), al mismo tiempo que le daba la capacidad de legislar por decreto. Pero con el objetivo de que éste no pudiera imponer su voluntad sin cortapisa alguna sobre el Parlamento, recogió la imposibilidad relativa de que disolviera las cámaras, pues dicha disolución vendría acompañada de un referéndum popular que podría provocar la pérdida del cargo: "En el presidencialismo pueden seguirse dos grandes caminos: o el presidente fuerte, a la alemana, o el presidente débil, a la francesa. El presidente fuerte es elegido por el pueblo, tiene el poder de legislar por decreto, puede en ciertos casos disolver la cámara...El presidente francés, de

existencia de los consejos, nada se podía hacer al respecto. vid. Luis Jiménez de Asúa, La Constitución de la democracia española y el problema regional, op. cit., pp. 51-52.

128 En el planteamiento de la supresión del Senado que recoge este voto particular estaba presente la idea de contar con un presidente de la República que fuera elegido lo más democráticamente posible. En este contexto, apoyarse en un Senado que en el anteproyecto aparecía como una institución que neutralizaba la voluntad del pueblo era del todo inconcebible. Además, a esta idea añadieron el hecho de que en la gran mayoria de las Constituciones del periodo de entreguerras se habían procedido a la eliminación del Senado por su carácter antidemocrático. Por lo tanto, el razonamiento último de los firmantes del voto particular se apoyó en la ida de que el Senado no respondía a ninguna realidad nacional, así como a ninguna exigencia doctrinal, por lo que su constitucionalización fue concebida como "la negación más absoluta de la voluntad de la nación". Vid. Voto particular al artículo 32 del anteproyecto de Constitución de la República española, Biblioteca virtual Miguel de Cervantes, disponible en línea.

129 Diario Sesiones de las Cortes Constituyentes, 27 de agosto de 1931, n 28, p. 646.

130 Luis Jiménez de Asúa, Proceso histórico de la Constitución de la República española, op. cit., p. 318.

131 Nicolás Pérez Serrano, La Constitución española. Antecedentes, textos, comentarios, op. cit., p. 245. 
tipo débil, es elegido por la Asamblea, reunidos la Cámara de Diputados y el Senado, y prácticamente no tiene facultades para disolver las cámaras. Nosotros tratamos de establecer una sintesis entre el presidente fuerte y el presidente débil. Al igual que en Alemania, es elegido por el pueblo, puede legislar por decreto, pero no puede disolver la cámara, porque en el último extremo tiene que ir a pedir el referéndum, el parecer popular, jugándose el cargo en la empresa"132. Se observa por lo tanto cómo, de nuevo, en un intento de racionalización y de búsqueda de equilibrio, Jiménez de Asúa tomó en consideración el contexto comparado, rescatando diferentes elementos que le permitieran construir un sistema eficaz para la estabilidad de la República. Sin embargo, a diferencia de lo ocurrido con la propuesta de unicameralismo, la idea de un presidente elegido por sufragio directo no salió adelante, optándose finalmente por una elección conjunta entre miembros de las Cortes y un grupo de compromisarios de igual número que los diputados.

Con el paso de los años Jiménez de Asúa lamentó gravemente este cambio, pues consideró que, en el momento en el que el Parlamento participaba en la elección del presidente de la República, éste quedaba peligrosamente subordinado al capricho de los diputados, dando la posibilidad de que la presidencia quedara "esclavizada" por el "poderío de la Cámara única". Entendia que si quizás una elección directa del presidente se hubiera estimado peligrosa, habria sido más conveniente optar por una segunda vuelta que por la solución tomada, con la cual, "el equilibrio de poderes que el proyecto buscaba quedó comprometido"133. Antes de cerrar el ámbito relativo a la organización institucional, hay un elemento que creo que es necesario reseñar aquí por el impacto que tuvo con el paso de los años en las instituciones republicanas en el exilio. En el proyecto presentado por la comisión se hacía referencia a la elección del vicepresidente de la República, el cual se elegiría por el mismo procedimiento que el del Presidente. No obstante, tras las discusiones parlamentarias, la figura del vicepresidente desapareció, debiendo encargarse el presidente de las Cortes de asumir temporalmente las funciones del presidente de la República en el caso de que algún impedimento concurriera, y asumiéndolas totalmente, en el caso de que quedara vacante, con la obligación de convocar elecciones en el plazo de ocho dias ${ }^{134}$. Teniendo en cuenta esta regulación, hay que avanzar hasta el año 1939, cuando, con la guerra prácticamente perdida por la II República, Manuel Azaña dimitió, quedando vacante la presidencia. Ya en el exilio, y con el objetivo de ocupar dicho vacío, Diego Martínez Barrios, presidente de las Cortes, accedió a la presidencia, pero sin convocar elecciones en el plazo de ocho dias que estipulaba la Constitución. La ausencia de elecciones y la permanencia de Diego Martínez Barrios en la presidencia se justificó alegando estado de necesidad; una decisión a la que Jiménez de Asúa, en su defensa férrea de la legalidad, se opuso fuertemente.

No obstante, Jiménez de Asúa siguió colaborando con las instituciones republicanas en el exilio, no solo en su cargo de vicepresidente de las Cortes (que

132 Diario de Sesiones de las Cortes Constituyentes, 27 de agosto de 1931, n 28, p. 646.

133 Luis Jiménez de Asúa, La Constitución de la democracia española y el problema regional, op. cit., p. 48.

134 Luis Jiménez de Asúa, Proceso histórico de la Constitución de la República española, op. cit., p. 357-358. 
ocupaba la presidencia de las Cortes en funciones, puesto que su antecesor había pasado a ocupar la presidencia de la República), sino que incluso llegó a ser nombrado ministro sin cartera tras la reunión de las Cortes en México en el año 1945. Pero el giro dramático de los acontecimientos tuvo lugar cuando Diego Martínez Barrios falleció en 1962, quedando vacante la presidencia de la República. Tras la muerte del político sevillano, Jiménez de Asúa accedió al cargo de presidente de la República, pero siempre se aseguró de dejar claro, en pos de la defensa de la Constitución republicana, que él no era sino el presidente de las Cortes republicanas, que ocupaba, en funciones, la presidencia de la República ${ }^{135}$.

\subsection{Justicia}

Si he decidido dejar la justicia fuera de la organización institucional planteada por el proyecto de la comisión, es por la condición de jurista de Jiménez de Asúa. Su dedicación, tanto docente como profesional, al mundo de la justicia, provocó que participara activamente en algunos debates relativos a temas judiciales, siendo capaz de anteponer el sentido común y la realidad material a algunos planteamientos que para él eran fundamentales en una justicia democrática y socialista. Para comprender el contexto, cabe decir que Jiménez de Asúa fue muy cercano al positivismo criminológico italiano y a la politica-criminal en sus primeros años como penalista. Atraído por instituciones criminales que se alejaban del derecho penal clásico, y que él relacionaba con la llegada del socialismo, durante buena parte de su etapa universitaria bajo el yugo de Primo de Rivera, apostó abiertamente por el fin de principios tales como el de legalidad; no desde una postura autoritaria, sino desde la visión utópica que le hacía creer que la sociedad había avanzado hasta tal punto que las conquistas de la revolución francesa debían ser dejadas atrás. De hecho, llegó a asumir como suyo el Derecho Protector de los Criminales de Pedro Dorado Montero, un sistema en el que, a grandes rasgos, se dejaban de lado buena parte de los principios penales clásicos en pos de la rehabilitación y la corrección de los criminales, que eran concebidos como enfermos en lugar de como reos, y las penas como tratamientos en vez de como castigos ${ }^{136}$; y que Jiménez de Asúa concebía como realizable bajo los principios del socialismo.

No obstante, experiencias como la dictadura de Primo de Rivera y el régimen fascista de Mussolini hicieron ver a Jiménez de Asúa que rechazar los principios del derecho penal clásico en aras de una justicia correccional de corte socialista podría traer consigo una pérdida de libertades irreparables. Fue así como, a pesar de concebir la II República como un periodo de transición entre el capitalismo y el socialismo, apostó por el mantenimiento de principios penales que, si bien seguian bebiendo de las conquistas de la revolución francesa e impedian la creación de una nueva justicia construida sobre instituciones como la sentencia indeterminada, conseguían que los derechos y libertades de los ciudadanos estuvieran protegidos frente a cualquier injerencia del ejecutivo.

135 Todos los pormenores en Enrique Roldán Cañizares, Luis Jiménez de Asúa. Derecho penal, República, Exlio, op. cit., pp. 64-66.

136 Para una mejor comprensión de la evolución penal de Jiménez de Asúa y su acercamiento, plenamente democrático a las instituciones positivistas, véase mi libro Enrique Roldán Cañizares, Luis Jiménez de Asúa. Derecho penal, República, exilio, op. cit., pp. 109-122. 
Con esta idea en mente, Jiménez de Asúa comenzó a desarrollar su trabajo como presidente de la comisión, siendo consciente de que existían líneas que no podian ser rebasadas por la conservación de la propia seguridad jurídica de los ciudadanos. De este modo, no tuvo ningún tipo de inconveniente en reconocer que se buscaba crear un poder judicial fuerte que sirviera de garantias al Estado de derecho; una pretensión que quedó reforzada con la elección del presidente del Tribunal Supremo a través de una asamblea conformada por representantes del parlamento, la Magistratura, las Facultades de Derecho y los Colegios de Abogados (propuesta que en el texto definitivo fue sustituida por una "asamblea constituida en la forma que determi[nara] la ley"). Asimismo, el reconocimiento constitucional del principio de legalidad, cambiando algunas de las palabras que lo recogian en el anteproyecto, pero manteniendo el espíritu ${ }^{137}$, fue la prueba irrefutable de que el derecho penal clásico de contenido liberal iba a seguir rigiendo la justicia española. Pero si hay algo que merece ser destacado (aunque finalmente no llegara a buen tiempo) de la aportación de Jiménez de Asúa a la construcción constitucional de la justicia, fue la abolición de la pena de muerte. Sin precedente en el anteproyecto, se introdujo desde la comisión en el artículo 27, del que se exceptuaba su aplicación en tiempos de guerra por parte de la jurisdicción militar.

Cabría preguntarse la razón que llevó a una persona que hasta el final de sus dias fue un "radical enemigo de la pena de muerte"138 a mantener la pena capital en tiempos de guerra. Y la respuesta no es otra que la defensa del principio de legalidad. En su construcción jurídica ideal, la pena de muerte no tendría ningún tipo de cabida, pero entendía que por su "disciplina férrea", la jurisdicción militar tenía unas características completamente distintas al derecho penal común. Por esa razón, en un mundo en el que la aplicación de la pena capital era prácticamente inherente a la justicia militar, no podría declararse la suspensión de la pena de muerte en tiempos de guerra, pues se acabaría produciendo su aplicación ilícita ${ }^{139}$. Por otra parte, diputados como Ossorio y Gallardo se pronunciaron en contra de su inclusión en el proyecto, puesto que entendian que, si una Constitución no incluía penas, mucho menos debía abolirlas. Jiménez de Asúa, en cambio, comprendió que su inclusión era más que necesaria, pues el problema de la pena de muerte había "extravasado el perímetro estricto y técnico del derecho penal", de manera que la pena de muerte (al igual que había ocurrido en Austria) podía ser considerada como una de esas materias que en el nuevo constitucionalismo, por darse una ampliación de los temas abarcables, tenía plena cabida en el texto constitucional ${ }^{140}$.

Otros dos aspectos que han de ser reseñados dentro del ámbito estrictamente judicial son el del rechazo a la constitucionalización de los indultos generales, principio que sí estaba recogido en el anteproyecto y que la comisión se encargó de eliminar, así como el rechazo de la justicia gratuita. En su alegato en contra del indulto se dejaba entrever su interés por aquellas instituciones

137 Luis Jiménez de Asúa, Proceso histórico de la Constitución de la República española, op. cit., pp. 74 y 222-223.

138 Luis Jiménez de Asúa, "La pena de muerte", en Cristina Rodríguez Yagüe (ed.), Clásicos españoles sobre la pena de muerte, Ciudad Real, Universidad de Castilla La Mancha, 2013, p. 155.

139 Diario de Sesiones de las Cortes Constituyentes, 29 de septiembre de 1931, n 46, p. 1293.

140 Diario de Sesiones de las Cortes Constituyentes, 30 de septiembre de 1931, n 47, p. 1310. 
novedosas que pudieran ayudar a la transformación del derecho penal clásico, tales como la sentencia indeterminada o la libertad condicional. Retomando la idea de que la República había de mudarlo todo, acabar con el indulto general, que no era más que un viejo remanente del poder monárquico, se convertía en tarea fundamental, apostando así por la corrección del delincuente en lugar de concederle la libertad como una medida de gracia ${ }^{141}$. En lo referente a la gratuidad de la justicia, nada decía el proyecto. Sin embargo, en el fragor de las discusiones parlamentarias salió a la palestra el asunto de la gratuidad de la justicia, defendido a capa y espada por Eduardo Barriobero. Jiménez de Asúa, en un alegato que llevó a que algunos diputados, en tono jocoso, pidieran una "tila para el presidente de la comisión", sostuvo que la justicia no podía ser gratuita porque era obvio que su funcionamiento requería de unos gastos que debian ser sufragados, de manera que su gratuidad supondría que fuera el pueblo llano a través de los impuestos el que lo terminara pagando. Defendió así la peligrosidad de injertar principios socialistas en un régimen capitalista, y las Cortes, siguiendo el alegato de Jiménez de Asúa, acabó incluyendo en el texto constitucional la gratuidad de la justicia solo para los "litigantes económicamente necesitados"142.

Finalmente, es necesario hacer mención al Tribunal de Garantías Constitucionales, el cual recibió el nombre de Tribunal de Justicia Constitucional en el anteproyecto, y se erigió como una novedad, pues no contaba con precedente alguno en la historia constitucional española, independientemente de que con el tiempo Javier Elola hablara de la figura del Justicia Mayor de Aragón como un "antecedente precioso de un valor extraordinario"143. Aun así, y a pesar del gélido recibimiento, el Tribunal de Garantías Constitucionales situó a España en la punta de lanza europea al incluir, igual que las Constituciones de Austria o Checoslovaquia, el modelo de justicia constitucional concentrado planteado por Hans Kelsen ${ }^{144}$. Lo cierto es que, a pesar del ejemplo del Tribunal austriaco, el propio Jiménez de Asúa reconoció que las mayores influencias que se habian recogido fueron las del "Tribunal Constitucional de Norteamérica [sic] ${ }^{145}$, Tribunal de Juicio de Amparo de México y el Tribunal de Conflictos de Francia"146. Asimismo, se dieron algunas diferencias notables entre el tribunal propuesto por el proyecto y el que finalmente rigió en España, siendo destacable la competencia para declarar la inconstitucionalidad de las leyes. Aunque finalmente sí fue recogida en el texto constitucional, el proyecto de la comisión no otorgaba tal facultad al Tribunal, sino que le daba la capacidad de denunciar la inconstitucionalidad en cuestión al presidente de la República, el cual deberia presentarla al Parlamento para, una vez conocida la decisión de éste, la confirmara o la llevara a referéndum. Se trataba, en definitiva, de que los tres

141 Diario de Sesiones de las Cortes Constituyentes, 18 de noviembre de 1931, n 76, p. 2430.

142 Diario de Sesiones de las Cortes Constituyentes, 13 de noviembre de 1931, n ${ }^{\circ}$ 74, p. 22372238.

143 Diario de Sesiones de las Cortes Constituyentes, 23 de mayo de 1933, n 342, p. 13004.

144 Héctor Álvarez García, "La naturaleza política del Tribunal de Garantías Constitucionales de la Segunda República Española”, Revista de Derecho político, n 80, 2011, pp. 189-200.

145 Estas son las palabras literales del discurso de Jiménez de Asúa, entiendo que para referirse la Corte Suprema.

146 Diario de Sesiones de las Cortes Constituyentes, 27 de agosto de 1931, n 48, p. 647. 
poderes participaran en la declaración de inconstitucionalidad, dándose aquí una nueva muestra de racionalización del poder.

\section{CONCLUSIONES. LA CONSTITUCIÓN QUE NO FUE}

La discusión parlamentaria llegó a su fin y el dos de diciembre se reunió la comisión con el objetivo de corregir el estilo y acoplar las enmiendas aceptadas. Tras trabajar diez horas diarias hasta el dia cuatro de diciembre, la versión definitiva fue mandada a imprenta, y finalmente fue aprobada el día nueve del mismo mes. La Constitución resultante fue concebida de forma mayoritaria como el acuerdo de socialistas y republicanos de izquierda ${ }^{147}$. Pero como es obvio, buena parte de la política española no encontró motivo de regocijo. Así, la izquierda más allá del PSOE la consideró un fraude al mantener el sistema económico capitalista, mientras que la derecha jamás perdonó el componente anticlerical $^{148}$. Independientemente de las críticas recibidas desde ampos espectros del campo político, no cabe duda de que la Constitución republicana, y por descontado el proyecto de la comisión presidida por Jiménez de Asúa, encontraron su marco en la construcción de los fundamentos del Estado democrático que persiguió el constitucionalismo de entreguerras ${ }^{149}$, llegando a romper definitivamente con el régimen precedente.

El nuevo, nacido en abril de 1931 y sustentado por la Constitución, ofrecía las herramientas para llevar a cabo la modernización politica y social de España, alcanzando a su vez la homologación con el constitucionalismo europeo ${ }^{150}$. La Constitución de 1931 dilató su ámbito jurídico y se asentó sobre la realidad social de una España que necesitaba acuciantemente una modernización severa, lo que la convertía en una norma que planteaba una ordenación jurídica completamente diferente a la que la última Constitución, la de 1876 , había recogido ${ }^{151}$. Esto supuso la atenuación de la distinción absoluta entre derecho público y derecho privado, algo que ya venía ocurriendo en otros países cuyas constituciones inspiraron la española, como son los casos de Alemania, Estonia, Checoslovaquia, Irlanda, Grecia y Yugoslavia ${ }^{152}$. De hecho, la referencia a Alemania no es casual, ya que, obviando las corrientes que apuntaban que la Constitución era la culminación de las constituciones progresistas del siglo XIX, lo cierto es que ésta fue engendrada por una generación de profesionales especializados en derecho politico que, o bien se habían formado en Alemania o

147 Luis Legaz y Lacambra, "El estado de derecho en la actualidad", Revista General de Legislación y Jurisprudencia, $\mathrm{n}^{\circ}$ 2, 1933, p. 722-797.

148 Manuel Pinto, "La Constitución de la República Española. Carácter y fisonomía" en Jurisprudencia Argentina, Sección Legislación Extranjera, n 322, tomo XXXVII, Buenos Aires, 1933, pp. 3-54.

149 Francisco Javier Corcuera Atienza, "La Constitución Española de 1931 en la historia constitucional comparada", op. cit., pp. 629-695.

150 Andoni Pérez Alaya, La Constitución republicana de 1931 siete décadas después, op. cit., p. 3.

151 Manuel Pinto, "La Constitución de la República Española. Carácter y fisonomía”, op. cit., pp. $3-54$.

152 Manuel Pinto, "La Constitución de la República Española. Carácter y fisonomía”, op. cit., pp. $3-54$. 
habían estado en contacto con autores alemanes de la talla de Preuss, Kelsen, Heller y Jellinek ${ }^{153}$.

Ante este contexto, es fundamental apuntar que la Carta Magna republicana no se limitó a reconocer derechos y libertades y a establecer una determinada forma de régimen político, sino que además sentó y marcó las directrices de un programa político cuyo objetivo fundamental no era otro que la regeneración de España ${ }^{154}$. El país necesitaba una reforma, y esta pasaba por la II República, que a su vez se apoyaba en la Constitución. En este sentido, destacan las palabras de Azaña al decir "que al darse esa Constitución, esas leyes y ese régimen, la República es la garantía de la sociedad y del orden en España, o se salva con la República, o perece con ella, y la República ha establecido en su Constitución y en su política aquellos cauces que permiten una transformación de la sociedad española, dentro de un régimen legal y dentro de una contienda parlamentaria..."155.

A lo largo del texto se ha podido observar cómo muchas de las propuestas que la comisión incluyó en el proyecto fueron desechadas por las Cortes; así como se ha apreciado que distintas proposiciones fueron incluidas sin que la comisión las hubiera trabajado previamente. De este modo, resultó una Constitución con la que Jiménez de Asúa no estaba plenamente satisfecho, pues llegó a decir que "prefería el proyecto de la comisión parlamentaria, por ser más orgánico, por establecer una manera más medida la diferencia de poderes y, sobre todo, el juego entre la presidencia y las Cortes". Lo cierto es que una de las grandes críticas que el profesor madrileño lanzó contra la Constitución fue la debilidad del poder ejecutivo. El contexto europeo y las ansias democráticas que surgieron tras el fin de la dictadura de Primo de Rivera exigian edificar un sistema parlamentario, pero con el tiempo y la perspectiva que da el exilio entendió que de ese empeño "surgieron consecuencias harto graves para el porvenir republicano ${ }^{156}$.

La segunda crítica fue la del exceso de liberalismo. Defensor de la democracia y de la libertad, habría sido imposible que un proyecto surgido de una comisión por él presidida no hubiera estado indeleblemente marcado por estos dos principios. Así, consideró que liberal fue la respuesta que la Constitución dio a los grandes problemas de la República que consigné en los primeros compases de este trabajo. Se respondió con politicas liberales al ejército, a la Iglesia, a los problemas regionales y a la reforma agraria; pero los grandes enemigos de la República, ejército, clero y terratenientes, aprovecharon el liberalismo de la República para conspirar contra ella. Tras unos primeros compases de acobardamiento, los tres poderes "provocaron el alzamiento que estranguló a la República y [que sumió] en el oprobio y en la miseria a España", e iniciaron una guerra que aún hoy tiene cicatrices sin curar y enterraron en el olvido a una Constitución elaborada por un penalista que tuvo el convencimiento,

153 Santos Juliá, La Constitución de 1931, op. cit., p. 75.

154 Ibid., p. 74.

155 Diario de Sesiones de las Cortes Constituyentes, 2 de febrero de 1933, n 288, p 10894.

156 Luis Jiménez de Asúa, La Constitución de la democracia española y el problema regional, op. cit., pp. $72-74$ y 78-79. 
incluso cuando extrañaba su patria desde el otro lado del Atlántico, de que "pudo haber dado horas de auténtica prosperidad a España"157.

\section{Bibliografia}

\section{Fuentes de Archivo}

\subsection{Archivo del Congreso de los Diputados}

Archivo del Congreso de los Diputados, P-01-000539-0001-0001-016. Archivo del Congreso de los Diputados, P-01-000539-0001-0020-003. Archivo del Congreso de los Diputados, P-01-000539-0001-0020-002. Archivo del Congreso de los Diputados, P-01-000539-0001-0019-001. Archivo del Congreso de los Diputados, P-01-000539-0001-0001-012 Archivo del Congreso de los Diputados, P-01-000539-0001-0006-001.

\subsection{Archivo Fundación Pablo Iglesias}

"El día de la raza", FPI, ALJA 436-17

"Conferencia sustentada por el doctor Luis Jiménez de Asúa, en la Sala de conferencias del palacio de las Bellas Artes la noche del 10 de febrero de 1943, organizada por Acción Democrática Internacional”, FPI, ALJA 435-1.

\subsection{Biblioteca virtual cervantes}

Anteproyecto de la Constitución de la República española.

\section{Diarios oficiales}

\subsection{Diario de Sesiones}

Diario de Sesiones de las Cortes Constituyentes, 27 de agosto de 1931, $\mathrm{n}^{\circ} 28$.

Diario de Sesiones de las Cortes Constituyentes, 18 de septiembre de 1931, n $^{\circ}$ 41.

Diario de Sesiones de las Cortes Constituyentes, 29 de septiembre de 1931, $\mathrm{n}^{\circ}$ 46.

Diario de Sesiones de las Cortes Constituyentes, 30 de septiembre de 1931, $\mathrm{n}^{\circ}$ 47.

157 Luis Jiménez de Asúa, Anécdotas de las constituyentes, op. cit., pp. 75-79. 
Diario de Sesiones de las Cortes constituyentes, 7 de octubre de $1931, \mathrm{n}^{\circ} 50$. Diario de Sesiones de las Cortes Constituyentes, 13 de octubre de 1931, n 55.

Diario de Sesiones de las Cortes Constituyentes, 13 de noviembre de 1931, n 74 . Diario de Sesiones de las Cortes Constituyentes, 18 de noviembre de 1931, n 76. Diario de Sesiones de las Cortes Constituyentes, 2 de febrero de 1933, $n^{\circ} 288$. Diario de Sesiones de las Cortes Constituyentes, 23 de mayo de 1933, n 342 .

\section{Fuentes bibliográficas}

Juan Enrique Albacete Ezcurra, El Estado integral de la Segunda República española, Murcia, Nausicaa, 2006.

Michael Alpert, La reforma militar de Azaña (1931-1933), Madrid, Siglo XXI.

Alfons Aragoneses, "Constitución y derecho civil en la Segunda República", en Luis I. Gordillo, Sebastián Martín y Victor Vázquez, Constitución de 1931: estudios juridicos sobre el momento republicano español, Madrid, Marcial Pons, 2017.

Luis Araquistain, "Anécdotas de la política. Cómo elaboramos el proyecto de Constitución”, El Sol, 8 de diciembre de 1931.

Manuel Azaña, Diarios completos: monarquía, república, guerra civil, Barcelona, Crítica, 2000.

Abraham Barrero Ortega, "La defensa extraordinaria de la República", Luis I. Gordillo, Sebastián Martín y Víctor Vázquez, Constitución de 1931: estudios juridicos sobre el momento republicano español, Madrid, Marcial Pons, 2017.

Andrés de Blas Guerrero, "El debate doctrinal sobre la autonomía en las constituyentes de la II República", Historia contemporánea, n 6, 1991.

Javier Corcuera Atienza, "El constitucionalismo de entreguerras y la Constitución española de 1931", Historia contemporánea, n 6, 1991.

Francisco Javier Corcuera Atienza, "La Constitución española de 1931 en la historia constitucional comparada", Fundamentos: cuadernos monográficos de teoría del estado, derecho público e historia constitucional, $\mathrm{n}^{\circ} 2,2000$.

Giacomo Demarchi, "Técnicos parlamentarios y Cortes constituyentes: Miguel Cuevas y Cuevas en la forja del constitucionalismo de la II República”, en Diana Repeto García, Las Cortes de Cádiz y la historia parlamentaria, Cádiz, Universidad de Cádiz, 2012.

Giacomo Demarchi, Provincia y territorio en la constituyente española de 1931, Madrid, Dykinson, 2019

Giacomo Demarchi, "La segunda república y su(s) territorio(s): los múltiples actores del Estado integral", en Luis I. Gordillo, Sebastián Martín y Víctor Vázquez, Constitución de 1931: estudios juridicos sobre el momento republicano español, Madrid, Marcial Pons, 2017.

Rafael Escudero Alday, Modelos de democracia en España. 1931-1978, Barcelona, Península, 2013. 
Rafael Escudero Alday, "Las huellas del neoconstitucionalismo. Democracia, participación y justicia social en la Constitución española de 19312, en Luis I. Gordillo, Sebastián Martín y Víctor Vázquez, Constitución de 1931: estudios jurídicos sobre el momento republicano español, Madrid, Marcial Pons, 2017.

Icíar Fernández Marrón, "Cartas de cuatro juristas republicanos a Miguel de Unamuno (1920-1936)", en Cuadernos de la Cátedra Miguel de Unamuno, n 33, 1998.

Luis Garrido González, "Constitución y reformas socioeconómicas en la España de la II República”, Historia contemporánea, n 6, 1991.

Miguel Ángel Giménez Martínez, "El régimen parlamentario de la Segunda República y las relaciones entre su presidente, el Gobierno y las Cortes", Hispania nova: revista de historia contemporánea, $\mathrm{n}^{\circ}$ 13, 2015.

Eduardo González Calleja, "La politización de la vida universitaria madrileña durante los años veinte y treinta”, en Eduardo González Calleja y Álvaro Rivagorda Esteban, La Universidad Central durante la Segunda República, Madrid, Dykinson, 2013.

Eduardo González Calleja, Francisco Cobo Romero, Ana Martínez Rus y Francisco Sánchez Pérez, La Segunda República española, Barcelona, Pasado y Presente, 2016.

Luis I. Gordillo, Sebastián Martín y Víctor Vázquez, "La segunda República desde el derecho ochenta y cinco años después", en Luis I. Gordillo, Sebastián Martín y Víctor Vázquez, Constitución de 1931: estudios jurídicos sobre el momento republicano español, Madrid, Marcial Pons, 2017.

Daniel Guerra Sesma, "El modelo territorial de las izquierdas en la Segunda República", Luis I. Gordillo, Sebastián Martín y Víctor Vázquez, Constitución de 1931: estudios juridicos sobre el momento republicano español, Madrid, Marcial Pons, 2017.

Javier Infante Miguel-Motta, "Un hito en la historia constitucional de España: el derecho de propiedad en la Constitución republicana de 1931", en Luis I. Gordillo, Sebastián Martín y Víctor Vázquez, Constitución de 1931: estudios jurídicos sobre el momento republicano español, Madrid, Marcial Pons, 2017.

Luis Jiménez de Asúa, Politica, Figuras, Paisajes, Madrid, Mundo Latino, 1927.

Luis Jiménez de Asúa, Libertad de amar y derecho a morir, Madrid, Historia nueva, 1928.

Luis Jiménez de Asúa, Juventud, Madrid, Velasco, 1929.

Luis Jiménez de Asúa, Notas de un confinado, Madrid, Editorial Mundo Latino, 1930.

Luis Jiménez de Asúa, "Retorno a la ciencia", La Libertad, 17 de abril de 1931.

Luis Jiménez de Asúa, “Constitución española y Estatuto catalán”, La Libertad, 29 de septiembre de 1931.

Luis Jiménez de Asúa, Proceso histórico de la Constitución de la República española, Madrid, Reus, 1932. 
Luis Jiménez de Asúa, Anécdotas de las Constituyentes, Buenos Aires, Publicaciones del Patronato hispano-argentino de cultura, 1942.

Luis Jiménez de Asúa, La Constitución de la democracia española y el problema regional, Buenos Aires, Editorial Losada, 1946.

Luis Jiménez de Asúa, "La pena de muerte”, en Cristina Rodríguez Yagüe (ed.), Clásicos españoles sobre la pena de muerte, Ciudad Real, Universidad de Castilla La Mancha, 2013.

Santos Juliá, Manuel Azaña. Una biografia politica, Madrid, Alianza editorial, 1990

Santos Juliá, La Constitución de 1931, Madrid, Iustel, 2009.

Luis Legaz y Lacambra, "El estado de derecho en la actualidad", Revista General de Legislación y Jurisprudencia, $\mathrm{n}^{\circ} 2.1933$.

Alicia López de los Mozos, "Igualdad de género en la Segunda República", en Luis I. Gordillo, Sebastián Martín y Víctor Vázquez, Constitución de 1931: estudios jurídicos sobre el momento republicano español, Madrid, Marcial Pons, 2017.

Joaquín López Rey, "La Constitución del trabajo en la Segunda República española", Luis I. Gordillo, Sebastián Martín y Víctor Vázquez, Constitución de 1931: estudios juridicos sobre el momento republicano español, Madrid, Marcial Pons, 2017.

Sebastián Martín, "Modernización doctrinal, compromiso técnico, desafección politica. Los juristas ante la Segunda República", en Luis I. Gordillo, Sebastián Martín y Víctor Vázquez, Constitución de 1931: estudios jurídicos sobre el momento republicano español, Madrid, Marcial Pons, 2017.

Sebastián Martín, “Autoconservación contra nación”, Revista de estudios politicos, $\mathrm{n}^{\circ} 82,2018$.

Boris Mirkine-Guetzévitch, "Prólogo" en Las nuevas Constituciones del mundo, Madrid, Ed. España, 1931.

Joan Oliver Araujo, "La Constitución republicana de 1931", Dereito: revista xuridica da Universidade de Santiago de Compostela, vol. 6, n 1, 1997.

Juan Oliver Araujo, "Las Cortes en la Segunda República española: luces y sombras 85 años después", Revista de derecho politico, n 102, 2018.

Andoni Pérez Ayala, "La Constitución republicana de 1931 siete décadas después", Bilbao, Cuadernos republicanos, n 19, 2002.

José Manuel Pérez-Prendes Muñoz-Arraco, Escritos de historia constitucional española, Madrid, Marcial Pons, 2017.

Nicolás Pérez Serrano, La Constitución española. Antecedentes, textos, comentarios, Madrid, Editorial Revista de Derecho Privado, 1932.

Nicolás Pérez Serrano y Adolfo González Posada, Las Constituciones de Europa y América, Madrid, V. Suárez, 1927.

Manuel Pinto, "La Constitución de la República Española. Carácter y fisonomía" en Jurisprudencia Argentina, Sección Legislación Extranjera, $\mathrm{n}^{\circ} 322$, tomo XXXVII, Buenos Aires, 1933. 
Adolfo Posada, La nouvelle Constitution espagnole, París, Libraire du Recueil Sirey, 1932.

Enrique Roldán Cañizares, Derecho penal, República, exilio, Madrid, Dykinson, 2019.

Francisco Tomás y Valiente, "El Estado Integral: nacimiento y virtualidad de una fórmula poco estudiada", en Obras Completas, III, Madrid, Centro de Estudios Politicos y Constitucionales, 1997.

Manuel Tuñón de Lara, "El sistema de partidos es 1931-1933", Historia contemporánea, $\mathrm{n}^{\circ}$ 6, 1991.

Sebastián Urbina Tortella, Ética y politica en Luis Jiménez de Asúa, Palma de Mallorca, Universidad de Mallorca, 1984.

Joaquín Varela Suanzes-Carpegna, "El constitucionalismo español en su contexto comparado", Documentos de Trabajo IELAT (Instituto Universitario de Investigación en Estudios Latinoamericanos), $\mathrm{n}^{\circ}$ 13, 2010.

Joaquín Varela Suanzes-Carpegna, "La Constitución de 1931 y la organización territorial del Estado", Iura Vasconiae, nº 10, 2013.

Víctor Vázquez, "El legado laico de la Segunda República española", en Luis I. Gordillo, Sebastián Martín y Víctor Vázquez, Constitución de 1931: estudios jurídicos sobre el momento republicano español, Madrid, Marcial Pons, 2017.

Pablo Lucas Verdú, La lucha contra el positivismo jurídico en la República de Weimar. La teoria constitucional de Rudolf Smend, Madrid, Tecnos, 1987.

Fecha de envío / Submission date: 15/01/2020

Fecha de aceptación / Acceptance date: 23/03/2020 